\title{
Categorical versus dimensional thinking: improving anti-stigma campaigns by matching health message frames and implicit worldviews
}

\author{
Jan-Hinrich Meyer ${ }^{1} \cdot$ Ko De Ruyter $^{2,3} \cdot$ Dhruv Grewal $^{4} \cdot$ Kathleen Cleeren $^{5} \cdot$ Debbie Isobel Keeling $^{6} \cdot$ Scott Motyka $^{7}$
}

Received: 2 April 2018 / Accepted: 27 June 2019 / Published online: 26 July 2019

(C) The Author(s) 2019

\begin{abstract}
Despite growing applications of social and healthcare marketing to enhance public well-being through anti-stigma campaigns, little research investigates how public stigma surrounding health conditions might limit the outcomes of these campaigns. By drawing on the theory of implicit worldviews, this study identifies reasons for public stigma as well as associated message frames to address these reasons. Study 1a provides evidence that implicit worldviews are relevant to campaign results. Study $1 \mathrm{~b}$ and Study 2 demonstrate that fitting consumers' implicit worldview with suitable (i.e., biomedical or biopsychosocial) health frames reduces stigma endorsement. Study 3 identifies the perceived severity of a mental illness as a boundary condition; marketing communications have the greatest impact when they refer to an illness with lower perceived severity. Finally, Study 4 expands understanding of the phenomenon by extending the findings to physical health conditions (i.e., obesity). The article concludes by discussing the implications of these findings for policy and future applications.
\end{abstract}

Keywords Social marketing · Mental illness · Stigma - Healthcare marketing · Message framing · Implicit worldviews · Biomedical model $\cdot$ Biopsychosocial model

Marketers can develop solutions to challenging societal problems (Andreasen et al. 2005; Lee and Kotler 2011), including wellbeing. For example, social marketing campaigns can target

Jan-Hinrich Meyer was part of Tecnológico de Monterrey, Campus Guadalajara, Mexico during the submission process of this paper. The first author collected and analyzed the data.

Martin Mende served as Area Editor for this article.

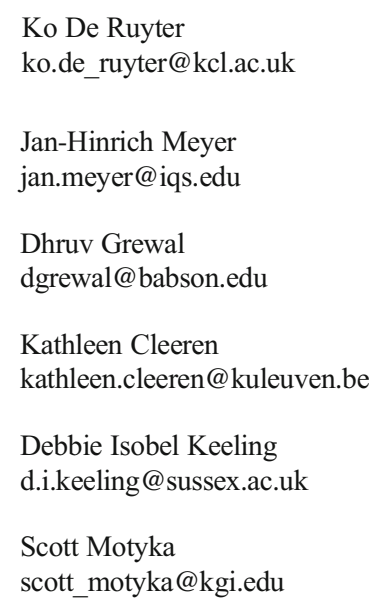

attitudes and behaviors related to schizophrenia, depression, suicide, smoking, alcohol abuse, and obesity (Kotler 2011). Most prior efforts have focused on individual behavioral changes, such
1 IQS School of Management, Universitat Ramon Llull, Via Augusta 390, 08017 Barcelona, Spain

2 King's Business School, King's College London, Bush House, 30 Aldwych, London WC2B 4BG, UK

3 School of Marketing, UNSW Business School, UNSW Sydney, Sydney 2052, Australia

4 Department of Marketing, Babson College, 213 Malloy Hall, Babson Park, MA 02457, USA

5 KU Leuven, Campus Carolus Antwerp, Korte Nieuwstraat 33, 2000 Antwerpen, Belgium

6 University of Sussex Business School, University of Sussex, Falmer Campus, Brighton BN1 9SL, UK

7 Keck Graduate Institute, 535 Watson Dr, Claremont, CA 91711, USA 
as encouraging a person with obesity to adopt healthier behaviors (e.g., healthier eating, smoking cessation; Zhao and Pechmann 2007) or calling for widespread preventative behaviors (e.g., cancer screenings, condom use; Freimuth et al. 1990; Schoenbachler et al. 1996). Although targeting communication efforts at (potentially) affected individuals can have some effect, it may be insufficient to achieve desired changes at a societal level, because more general stigmatizing attitudes often impede the effects of individual-level campaigns (Puhl and Heuer 2010).

This sort of public stigma refers to "prejudice and discrimination endorsed by the general population that affects a person" (Corrigan et al. 2012, p. 963), expressed as part of an effort to gain social distance "as a behavioral response" from the stigmatized person (Corrigan et al. 2001, p. 953). Public stigma is widespread. Moses (2010) shows that $62 \%$ of adolescents with mental illness experience stigmatization from peers, and $46 \%$ had similar stigmatizing experiences with family members. Similarly, $65 \%$ of obese children experience stigma in school, and $54 \%$ of obese workers report discrimination at work (WHO 2017b). The negative effects of such public stigma include treatment delays or refusal, greater symptom severity, and suicide risks due to isolation (Yanos et al. 2010). Furthermore, the global estimated economic cost of untreated mental illnesses for 2011-2030 will reach US\$16.3 trillion (WHO 2013, 2017a). Public stigma surrounding health conditions thus remains a major impediment to both the effectiveness of interventions (by reducing individual treatment adoption) and realizing long-term societal benefits (by creating greater health disparities) (Booth 2017; Puhl and Heuer 2010; WHO 2017a), highlighting the imperative to diminish public stigma.

Reducing public stigma related to mental illnesses is more challenging than similar efforts in relation to physical ailments, because the general public has limited knowledge about mental illnesses (Crisp et al. 2005). As evidence of this general phenomenon, we list 21 prominent, large-scale, global, anti-stigma social media campaigns in Table 1 . They reached almost 3 million followers on social networks, span 14 different countries on 3 continents, and have been in place for a decade or more. Yet empirical evidence suggests they have short-lived, weak effects, if any (Arboleda-Flórez 2017; Corrigan 2012). For example, the U.K.-based \#TimeToChange campaign (Evans-Lacko et al. 2013) failed to achieve its objective of consistently lowering public stigma endorsements, despite its vast reach. Therefore, we seek to develop a theoretically informed approach to the design and deployment of campaigns that tackle public health stigma, by matching the right message with the right recipient, as well as shed light on why many public-level campaigns fail.

Despite the critical impacts of public stigma (WHO 2017a), surprisingly little research in the social marketing field focuses on it, or on mental health issues in general. Existing studies that address individual behaviors often provide recommendations that explicitly seek to leverage the personal stigma associated with an undesirable behavior, such as smoking or poor diet, and prevent its normalization in wider society (Lin and McFerran 2016). These strategies achieve questionable success; they even can evoke adverse reactance and increase the undesirable behavior (Friedman and Puhl 2012). By focusing solely on individual behavioral changes, such research also ignores the potential outcomes of inducing societal-level changes, such as shifts in collective attitudes toward mental illness or obesity (Puhl and Heuer 2010). Some evidence suggests though that individual-level interventions, such as weight management campaigns, can achieve better outcomes if they are accompanied by large-scale campaigns to reduce public stigma related to the condition (Hanisch et al. 2016).

Therefore, we draw on theories of implicit worldviews, that is, the perceptions that people hold about themselves and others that determine whether they perceive their environment as categorical or dimensional (Chiu et al. 1997). These viewpoints inform attitude formation and decision making, especially in relation to stereotypes and stigmatizing attitudes, and affect how people process new information (Lyndon et al. 2016; Plaks et al. 2005). Through this substantive theoretical lens, we examine some causes of public stigma and some previously unexamined effects that might inform stigma reduction strategies.

Noting the persistent debate in social marketing about which message frames are most effective for reducing stigma (Kvaale et al. 2013), we integrate message frame theory and argue that different frames differentially affect the levels of stigma expressed by dimensional versus categorical thinkers. Specifically, we note two perspectives on the etiology of illness, dominant in healthcare and education settings: biomedical and biopsychosocial (Jaini and Lee 2015; Kiesler 1999). By integrating worldviews with health frames, we test whether the heterogeneous stigma reduction of social marketing campaigns reflects a (mis)match between the health message frame and the receiver's implicit worldview. If implicit worldviews affect people's reception of a campaign, anti-stigma communication designs should incorporate this factor to achieve stronger results.

With this empirical examination of determinants of effective communication strategies to reduce public stigma, we offer four key contributions. First, we help explain the mixed results of anti-stigma campaigns; they might stem from the failure to acknowledge distinct implicit worldviews. By applying implicit worldviews to mental illness, we identify an important individual difference that can predict stigma (Study 1) and explain people's resistance to campaigns. Second, we identify a new, effective strategy for overcoming negative attitudes among categorical thinkers, rather than priming them with a dimensional worldview. When specific message frames (biomedical vs. biopsychosocial) fit the recipient's worldview (categorical vs. dimensional), they are more effective for reducing stigma (Study 2), particularly for illnesses perceived to be low in severity (Study 3 and 4). To the best of our knowledge, this study is the first to explore the ways in which message frames might reduce stigma endorsement among dimensional thinkers, as 


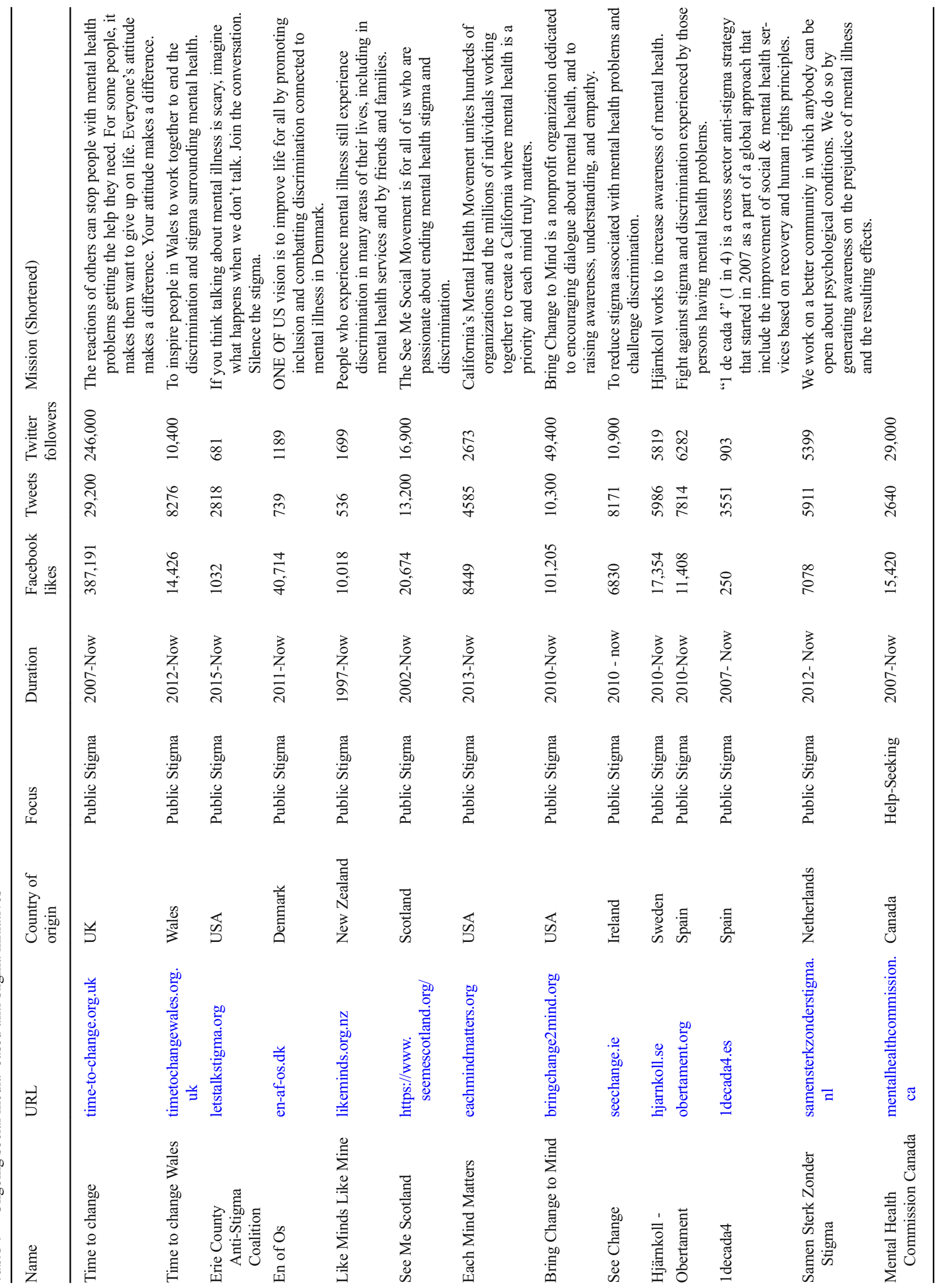




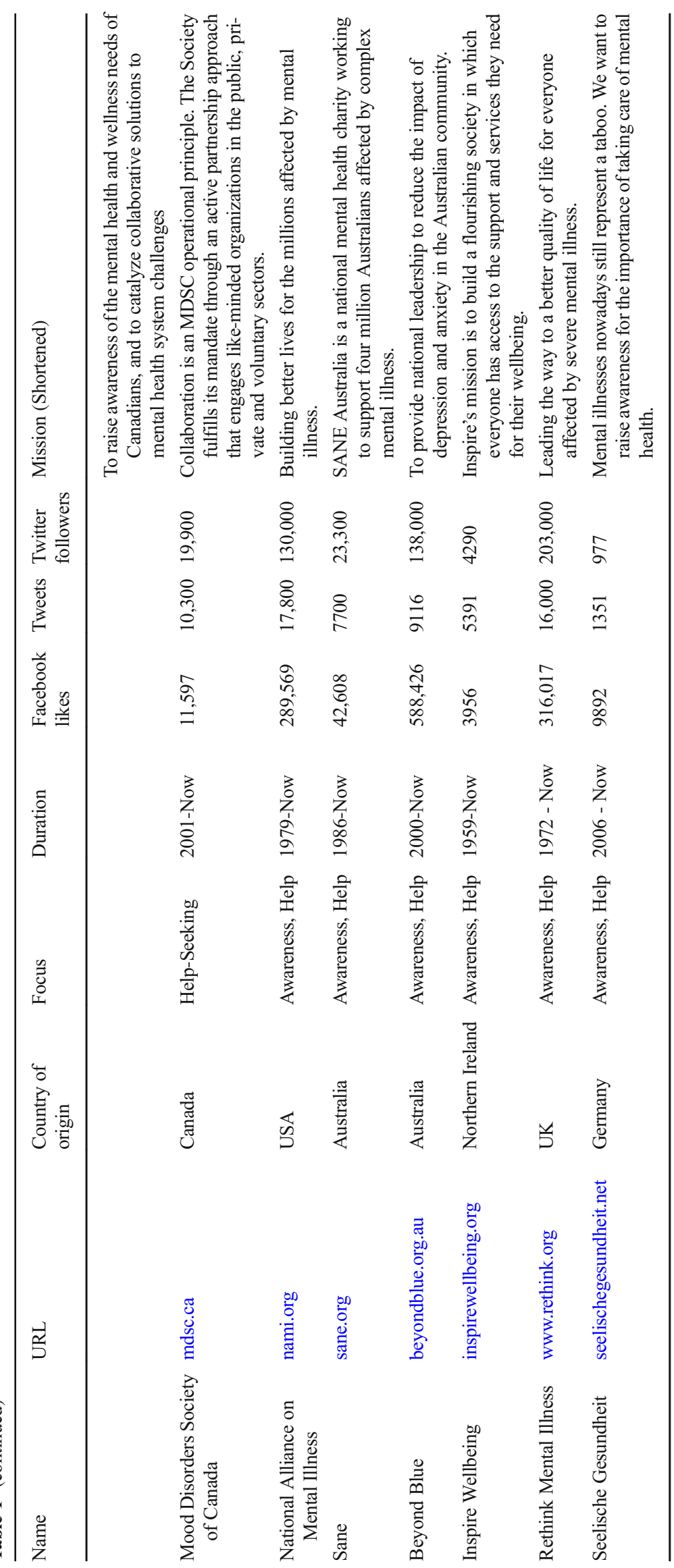


well as the first to test the comparative effectiveness of biomedical and biopsychosocial frames directly. Third, we identify perceived illness severity as an important boundary condition: Our results hold for mental illnesses perceived as less severe but not those perceived as severe (Study 3). We corroborate our findings in a relevant physical illness context (i.e., obesity; Study 4). Fourth, we contribute to social marketing literature by expanding the focus to considerations of public stigma in contrast with prevalent health communication campaigns that solely target people affected by the condition. We thus offer guidance for practitioners and open a promising avenue for social marketing research.

In the next section, we locate our contributions within the relevant theoretical context, pertaining to the relationship between public stigma and implicit worldviews. We then identify relevant mental illness message frames and assess their usage, as well as their immediate responses, through a preliminary field study. We then consider the potential fit between implicit worldviews and mental illness message frames and hypothesize how it might reduce public stigma through social marketing communications that manifest this fit. We present the empirical results of our four studies, a meta-analysis of the results of our various studies, and then conclude by discussing the theoretical, public policy, and managerial implications that emerge from our research.

\section{Theoretical development}

Persuasive health communication messages have received considerable attention in commercial and social research domains (Keller and Lehmann 2008; Rüsch and Xu 2017), as we summarize in Table 2. Such messages tend to be more successful when their frames match recipients' characteristics, such as a self-regulatory orientation (Daryanto et al. 2010). Similarly, we predict that when a message matches recipients' worldview, it "feels right" and induces stronger effects, whereas a mismatch likely attenuates these effects (Adnsager et al. 2001; Motyka et al. 2014; Zhao and Pechmann 2007). We know of no prior research that highlights these individual differences when investigating tactics to reduce public stigma, despite their likely influences on stigma formation (Rüsch and Xu 2017; Szeto and Dobson 2010).

\section{Implicit worldviews as antecedents of public stigma}

Implicit theories are central to a person's way of understanding the world (Rattan and Georgeac 2017), such that they prompt people to view individual traits as either categorical or dimensional (Chiu et al. 1997). People who see traits as categorical display black-and-white thinking; for example, they believe intelligence is a fixed trait, determined at birth. Categorical thinkers also expect consistency and predictability from a static environment. People who see traits as dimensional instead consider a multitude of variables and display more fine-grained, shades-of-gray thinking; they view intelligence as something to be developed over time (Chiu et al. 1997; Hong et al. 1995). With their dynamic view of the world, these dimensional thinkers accept inconsistencies and change (Lyndon et al. 2016; Plaks et al. 2001). Such implicit worldviews in turn affect people's judgments, motivation (Jain et al. 2009), affect regulation (Labroo and Mukhopadhyay 2009), and education (Ambrose 2017); they also extend beyond personality traits to affect health-related beliefs (Wang et al. 2009).

Noting that stereotype formation is a crucial antecedent of stigma development, Levy et al. (1998) find that categorical thinkers tend to make more extreme trait-based judgments of a target based on limited information, due to their static thinking. This mechanism affects the perceptions of not just individuals but entire groups, leading to stereotype development and ultimately public stigma (Byrne 2000). Even if categorical and dynamic thinkers are equally aware of the stereotypes, the former endorse both positive and negative stereotypes at higher levels, prototypical of their worldview. These findings hold across different settings and contexts, including racial stereotypes and views of religious or ideological groups (Levy et al. 1998; Plaks et al. 2001).

Implicit worldviews also influence responses to social marketing campaigns. According to Plaks et al. (2005), it is extremely difficult to convince categorical thinkers to let go of their stereotypes, because they anticipate the stability of traits and human personality and struggle to engage in more finegrained thinking (Hong et al. 1995). Therefore, implicit worldviews likely define how stigmatizing attitudes form (Rüsch et al. 2010), and categorical thinkers tend to adopt stronger stigmatizing attitudes. For example, they likely reject or ignore information about advanced treatments and improved prognoses, because their confirmation bias leads them to process only information that is consistent with their already held beliefs (e.g., "people with mental illness are bad and can't change," Lyndon et al. 2016).

Next to the well-known and often replicated finding that familiarity with mental illness or mentally ill people lowers public stigma on an individual level (e.g. Corrigan 2004, 2012; Corrigan et al. 2012 and Schomerus et al. 2007), limited research considers relevant personality traits as potential moderators in anti-stigma campaigns though, despite some evidence of their effects (Sampogna et al. 2017). Public stigma, as we define it, implies discriminatory attitudes among a general population toward a certain group of individuals, which lead to increased distance. Seeking such social distance implies behavioral intentions to avoid or discriminate against mentally ill people (Corrigan 2004). Social distance is an ultimate public stigma state, and its implications for behavioral intentions make it particularly relevant, because mentally ill people suffer acutely when a public stigma against them is 


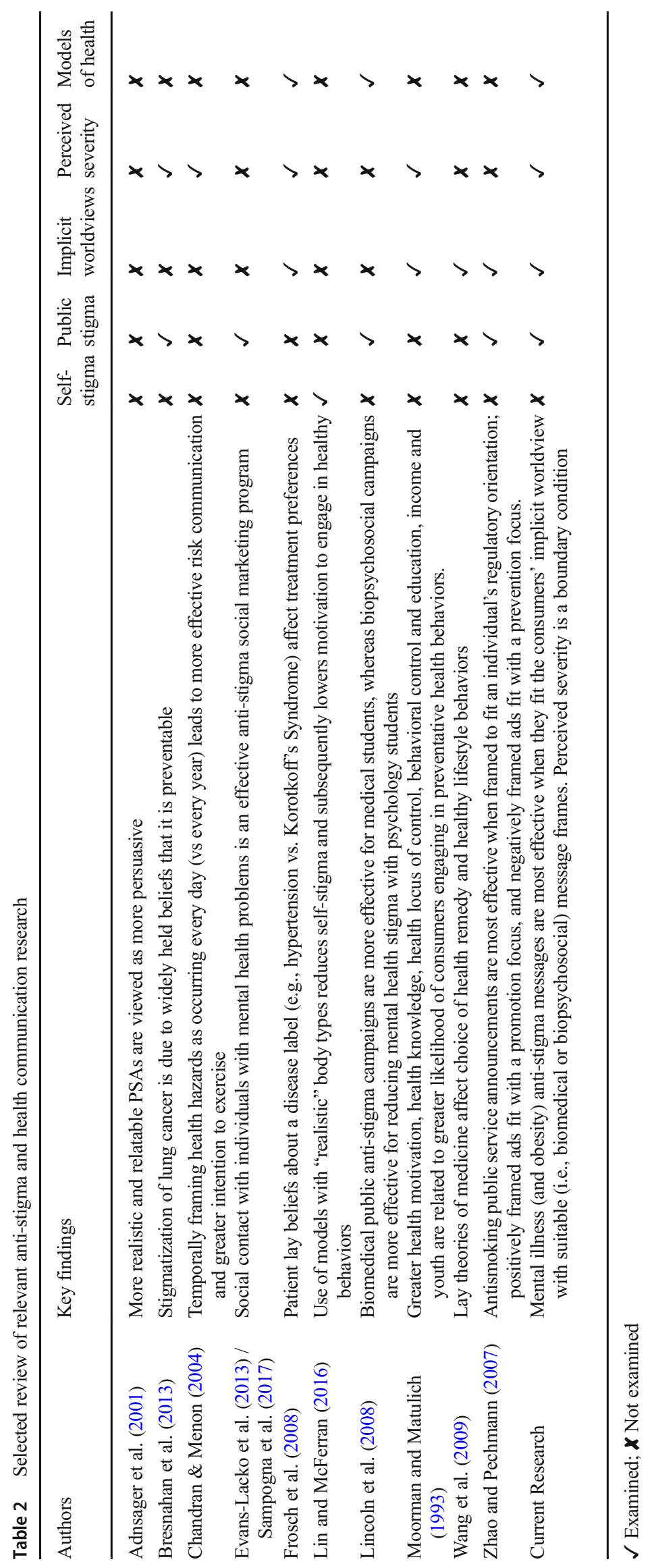


openly manifested (Corrigan 2004). Furthermore, though public stigma pertain to groups, social distance attitudes relate to individual members of those groups. By considering personality difference, we thus leverage an individual-level perspective on public stigma against mental illness.

On this individual level, we predict that the confirmation bias displayed by categorical thinkers leaves them more likely to ignore counter-stigma information that challenges their worldview, which prioritizes consistency and predictability (Lyndon et al. 2016; Plaks et al. 2001). That is, categorical thinkers view the world in fixed states (Lyndon et al. 2016) and judge categories rigidly (i.e., something is either entirely "good" or entirely "bad," without any middle ground), so they continue to demonstrate their sense of stigma in response to anti-stigma campaigns. In contrast, dimensional thinkers take a more dynamic view, do not simply regard anyone with mental illness as "bad," and accept inconsistency (Jain et al. 2009), so they may display less stigma endorsement, and the antistigma campaign messages align with and reinforce this worldview. We hypothesize:

H1: Categorical thinkers exhibit more public stigma, measured by social distance, than dimensional thinkers after both groups have been exposed to counter-stigmatic information.

\section{Health message framing}

Prior efforts to frame health communication messages to reduce public stigma yield mixed results (Arboleda-Flórez 2017; Corrigan 2012; Keller and Lehmann 2008), possibly due to the unintended consequences that arise depending on the representation of the etiology of the illness (i.e., causes). Two main health frames exist for the conceptualization of disease and associated health communication activities: the biomedical and biopsychosocial models. Both frames have the potential to reduce stigma about the responsibility of people diagnosed with mental illnesses but also may inadvertently increase stigma related to treatments and prognoses (Kvaale et al. 2013).

A biomedical message frame focuses on physiological origins and describes an illness as universal, across cultures and times. This frame could combat public stigma that arises due to a lack of knowledge or understanding of the condition, by emphasizing a single, clear-cut cause (Corrigan 2004), and it could reduce attributions of blame toward people with these conditions. The biomedical model does not view illness as a moral shortcoming or a reflection on the person's traits and abilities, such as self-control (Lincoln et al. 2008). Yet the simplicity of this biomedical perspective also could prompt a categorization of people diagnosed with mental illnesses into broad disease states, which can lead to stigma; being tagged with the illness might be perceived negatively (Rüsch et al. 2010).
Instead, the biopsychosocial message frame represents illness as fuzzy, with multiple potential causes, marked by boundaries and interlinkages (e.g., co-morbidities with other mental or physical ailments). In this view, conditions such as mental illness result from individual circumstances that vary across cultures and time and are often situational in nature (Haslam et al. 2002). Biopsychosocial messages highlight the individual experience of the patient and illness, with a focus on psychological and social causes, not just biological determinants (Ghaemi 2009), which could have stigmareducing effects. Such messaging shifts the receiver's focus from a generic stereotype of people with the condition to a more detailed understanding of individual cases and causes, which may prevent generalizations and reduce stigma formation (Read et al. 2006). Yet emphasizing the complex etiology of conditions may create an overly vague view among message recipients (e.g., too many determinants) or hinder their understanding due to message complexity, which then could lead to greater public stigma (Ghaemi 2009).

Exploratory study of secondary data Both types of messages have unique strengths and weaknesses (Ghaemi 2009; Rüsch et al. 2010). They also are both prevalent in practice. We examined 259 posts by the U.K.-based \#TimeToChange campaign (largest public stigma reduction campaign conducted via social media) for a 52 -week period (January 1 December 31, 2018), along with their engagement metrics (number of likes, comments, and shares). ${ }^{1}$

A key objective of this exploratory study was to understand how prevalent these two types of messages, and how they influence reader engagement. Using a codebook designed in conjunction with an expert health psychologist (non-author), two independent coders, who were authors, then classified the posts. We found that these posts consistently used both biomedical (51) and biopsychosocial (194) health message frames. In three ordinary least squares (OLS) regressions, we further found that biomedical (relative to biopsychosocial) messages result in greater likes, shares, and comments, as well as enhanced engagement. ${ }^{2}$ The results in Table 3 indicate that

\footnotetext{
${ }^{1}$ Two coders categorized posts ( $82 \%$ agreement) as biomedical, biopsychosocial, or non-health framed messages. The 14 messages $(5.4 \%)$ identified as non-health framed were dropped from the analysis, yielding 245 posts in the final sample.

${ }^{2}$ Customer engagement is a viral, exponential phenomenon (Berger 2011), so we used a natural $\log$ transformation of the dependent variables. In addition, the data span the course of a year, so we controlled for trends that might be due to seasonality fluctuations or changes to the algorithm. We also controlled for different content and post types (links, photos, videos). Then we coded the posts as stories of people affected by mental illnesses, information about mental illness, event notifications (e.g., mental illness awareness week), or calls to action issued to the general public. The three OLS models are significant $\left(F(17,227)_{\text {Likes }}=4.03, p<.01\right.$, adj. $R^{2}=.17 ; F(17,227)_{\text {Shares }}=7.72, p<.01$, adj. $R^{2}=.32 ; F(17,227)_{\text {Comments }}=2.25, p<.01$, adj. $\left.R^{2}=.08\right)$. The effect of biomedical messages is positive and significant for likes $\left(\beta_{\text {standardized }}=.17\right.$, $p<.01, r=.179)$ and shares $\left(\beta_{\text {standardized }}=.16, p<.01, r=.190\right)$ and marginally significant for comments $\left(\beta_{\text {standardized }}=.11, p<.1, r=.110\right)$.
} 


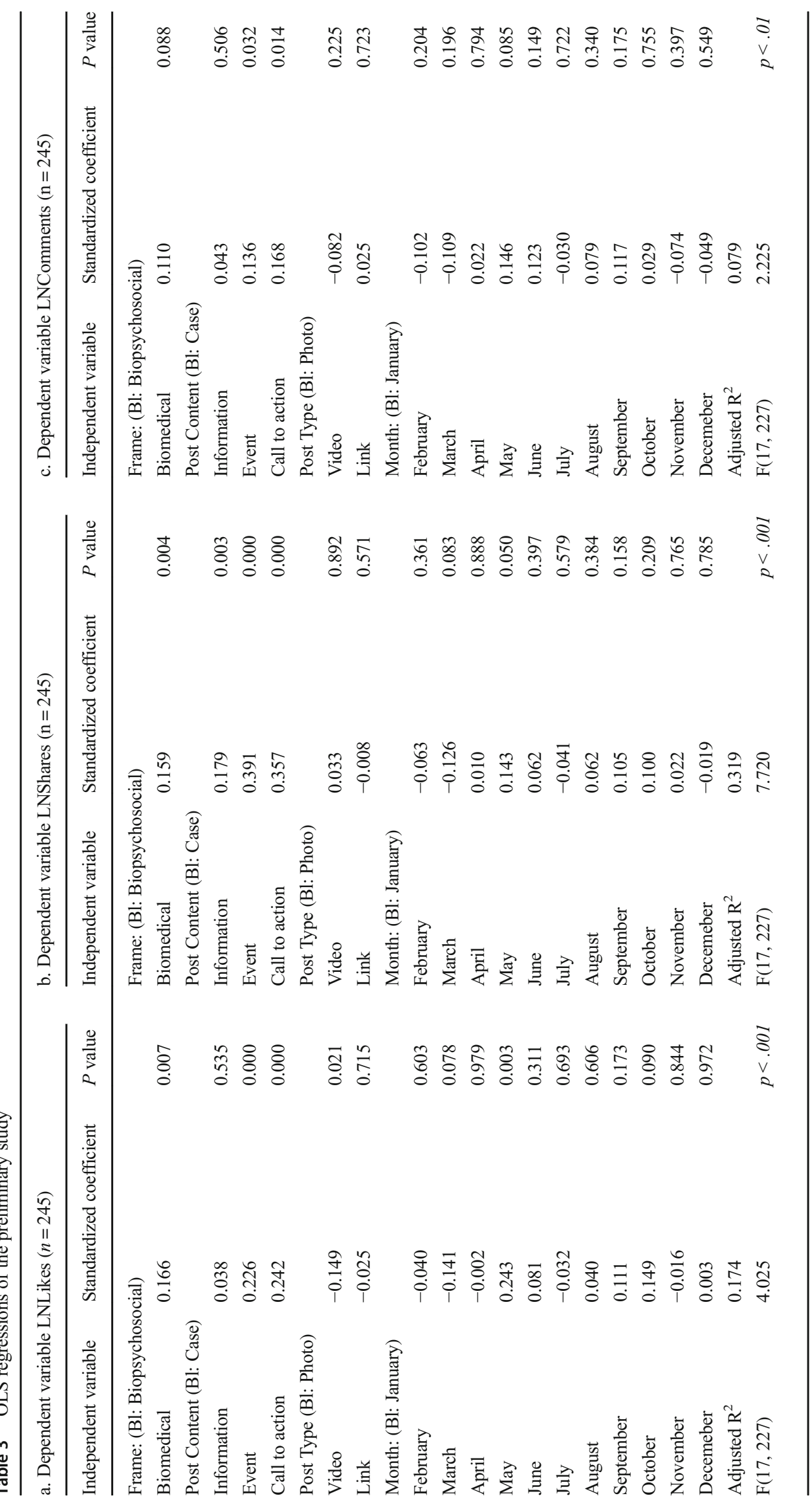


biomedical messages tend to evoke greater engagement than biopsychosocial messages, yet the \#TimeToChange campaign uses more biopsychosocial stimuli. Therefore, this study shows the relevance of both, the practical usage of the identified message frames as well as their potential impact on a viewer's reaction.

\section{Implicit worldviews and health message framing}

Marketing messages are more persuasive when their frame matches the target's personality (Daryanto et al. 2010). A message that resembles the recipient's own attitudes seems more familiar, which increases the cognitive ease of processing it, makes the message feel right (Higgins 2005), and causes it to appear more convincing, by evoking positive feelings and fewer doubts about its truthfulness. In contrast, a message that violates a person's worldview seems unfamiliar, feels wrong, and causes more skeptical reactions and increased stigma (Kahneman 2011; Plaks et al. 2005). Thus, counter-stigmatic information presented with a health message frame that fits recipients' worldviews could prompt both types of implicit theorists to process the messages distinctly. A matching message frame can offer an actionable means to overcome categorical thinkers' reluctance to process antistigma information; in contrast, a dimensional thinker's worldview would be violated by information that suggests a person cannot change certain traits, including mental illness (i.e., biomedical frame; Bastian and Haslam 2006), which could lead to increased stigmatization. Either biomedical or biopsychosocial framing thus may match (or mismatch) a person's implicit worldview.

Biomedically framed messages provide unambiguousness, clarity, and a categorical structure (Ghaemi 2009). Categorical thinkers view the world as static and uniform, so they should prefer messages that emphasize compatible illness attributes, such as (1) traits that provide clearly diagnosable signals (Chiu et al. 1997), (2) observations that can be generalized from individuals to groups (Levy et al. 1998), and (3) a sharp contrast between good and bad (Plaks et al. 2001). Accordingly, whereas a biopsychosocially framed message is unlikely to reduce public stigma endorsement by categorical thinkers, because it does not align with their worldview (Plaks et al. 2005), a biomedical model reflects their static, categorical worldview and thus should work particularly well (Dweck et al. 1995). We predict that categorical thinkers process counter-stigmatic information better if information is framed as a biomedical message.

For dimensional thinkers, the contextual and individual focus of the biopsychosocial message frame is more in line with their worldview, which encourages them to make fewer generalizations and assigns more importance to the context (Chiu et al. 1997). The focus on individual cases and room for interpretation also accords closely with the nuanced judgments that dimensional thinkers prefer (Dweck et al. 1995). In contrast, with a biomedical message frame, even if they endorse stereotypes less overall, dimensional thinkers may increase their stigma endorsement in response to this violation of their worldview, particularly if it primes them to adopt more categorical thinking (Bastian and Haslam 2006). By depicting illnesses in isolation from the context, this frame could foster a sense of powerlessness or inability to change (Read et al. 2006), with the related sense that mental illness is uncontrollable. Formally,

H2a: Categorical thinkers exhibit lower levels of public stigma, measured by social distance, after being exposed to a biomedical frame message rather than a biopsychosocial frame message.

H2b: Dimensional thinkers exhibit higher levels of public stigma, measured by social distance, after being exposed to a biomedical frame message rather than a biopsychosocial frame message.

\section{The moderating role of illness severity}

Stigma exists for many types of illnesses (Teachman et al. 2006), and perceived illness severity alters stigma perceptions (Gaebel and Zäske 2006). Illnesses vary in the degree to which they affect a person's ability to perform normal life tasks and thus the degree or type of stigma they invoke. Illnesses with lower perceived severity (e.g., mild anxiety) may prompt a sense that affected people are not really ill or should be able to 'pull themselves together'. More severe disorders (e.g., autism) are more widely accepted as illnesses, but they also cause increased stigma, related to fears of unpredictable behaviors by affected persons (Gaebel and Zäske 2006). Moreover, perceived severity varies across observers, so notable differences might arise in perceptions of the severity of the same disease category. Depression might be regarded as a temporary phenomenon that is treatable and manageable or a severe condition with extreme potential consequences (e.g., suicide). In a similar sense, obesity might be perceived as a rather mild condition, causing arthritis and digestive problems, or as a severe condition that increases cancer and stroke risks. Therefore, we explore how illness severity perceptions, both between diseases and within the same condition, interact with implicit worldviews and message frames.

When an illness is perceived as less severe, people diagnosed with that illness often do not display significant impairments in their daily life functions. ${ }^{3}$ Significant impairments are a necessary but not sufficient criterion for diagnoses, and

\footnotetext{
${ }^{3}$ As measured by the Diagnostic and Statistical Manual 5 (DSM-5) World Health Organization Disability Assessment Schedule 2.0 (WHODAS 2.0; Gold 2014)
} 
conditions perceived as low in severity often generate debate about whether they warrant a diagnosis (Coffey et al. 2011). The debate about whether an impairment is a diagnosable condition likely affects categorical thinkers more than dimensional ones; with their black-and-white worldviews, they reject loosely defined constructs (Plaks et al. 2001). Ambiguity about whether an illness is severe may lead categorical thinkers to exhibit more public stigma when they consider a biopsychosocial message but not when they receive a biomedical message, which gives them clear information to overcome the initial ambiguity. Dimensional thinkers instead may be more persuaded by nuanced, biopsychosocial messages rather than a categorical, biomedical perspective, because it fits their nuanced, dimensional worldview.

In contrast, if an illness is perceived as severe, the impairment of daily functioning likely makes the detrimental effects on people's lives more visible and salient to others, negating any diagnostic ambiguity (Coffey et al. 2011). A general consensus about the abnormality of behaviors displayed by a person with a severe illness could provoke persistent public stigma (Socall and Holtgraves 1992), which would be hard to change for either implicit worldview. Therefore, we expect no significant differences across implicit theories, regardless of the message used, when the mental illness is perceived as severe. We hypothesize:

H3: When illness is perceived as low in severity, a biomedical (biopsychosocial) message frame presented to categorical (dimensional) thinkers reduces stigma endorsement in comparison with a biopsychosocial (biomedical) message. This effect is attenuated for illnesses perceived as severe.

To test these hypotheses, we present four studies below. In Study 1 we analyze the relevance of both implicit theories and message frames using survey-based data. In Study 2 we consider the interactions of message frames (biomedical or biopsychosocial) with implicit worldviews. We then explore the effects of perceived severity on the reception of antistigma messages in relation to implicit worldviews, using both a between-illness comparison and a within-illness manipulation (Studies 3 and 4). Overall, we present five studies to test our hypotheses, and Table 4 provides an overview of the hypothesis testing results.

\section{Study 1: Establishing the relevance of implicit theories and message framing}

First, we establish that categorical thinkers display more stigma on average, even after they have been exposed to neutral anti-stigma campaigns (Study 1a), testing H1. Subsequently, we follow up with Study 1b, in which we expose consumers to actual campaign stimuli using the identified message frames to assess the interaction of implicit worldviews and message frames on stigma endorsement, formally assessing H1, H2a, and $\mathrm{H} 2 \mathrm{~b}$.

\section{Study 1a}

Design and procedure We assessed the implicit theory of our respondents gathered from Amazon's Mechanical Turk (MTurk) and then exposed them to a purely informational (neither biopsychosocial nor medical) anti-stigma campaign (Appendix A) and received 217 complete questionnaires. An attention check at the end of the study, in which we asked if respondents had honestly evaluated all the measures, along with a note that a negative response would not affect their compensation, led us to delete 12 responses, for a final sample of 205 respondents. Respondents were 33 years of age on average and $62 \%$ of them were men. Furthermore, $49 \%$ of respondents had an undergraduate university degree, and 98\% were from the United States. We asked them to assess their own implicit worldview (Dweck et al. 1995), prior to any other measures.

Dependent measure After completing the implicit theory measure and seeing the advertisement, respondents completed a seven-item social distance scale that indicated their willingness to interact with mentally ill people (Link et al. 1999; Appendix B), an often-used measure of public stigma. The items relied on seven-point Likert scales. We also gathered demographic information and assessed respondents' familiarity with mental illnesses, using a seven-item measure of how many contact points with mental illnesses a respondent had throughout his or her life, which we summed into an index (Schomerus et al. 2007; Appendix B).

Coding and reliability Responses to the implicit theory measure were highly reliable (Cronbach's $\alpha=.87$ ). We calculated the average of the three items to measure participants' chronic implicit worldview; higher values represent more categorical thinking. The stigma measure achieves good reliability $\left(\alpha_{\text {SocialDistance }}=.84\right)$ and is coded such that higher scores indicate a more stigmatizing attitude toward mental illnesses.

Results and discussion With an OLS regression (adjusted $R^{2}=.14$ ) that controls for familiarity with mental illness, we examined the effect of implicit worldviews on people's public stigma. Categorical thinkers demonstrate more stigma than dimensional thinkers $(\beta=.193, S E=.077 ; p<.05, r=.17)$, supporting H1 that current campaigns are insufficient to eliminate the difference in stigma between dynamic and categorical thinkers. Mental illness familiarity is significant, where lower levels of stigma arise from participants with more 


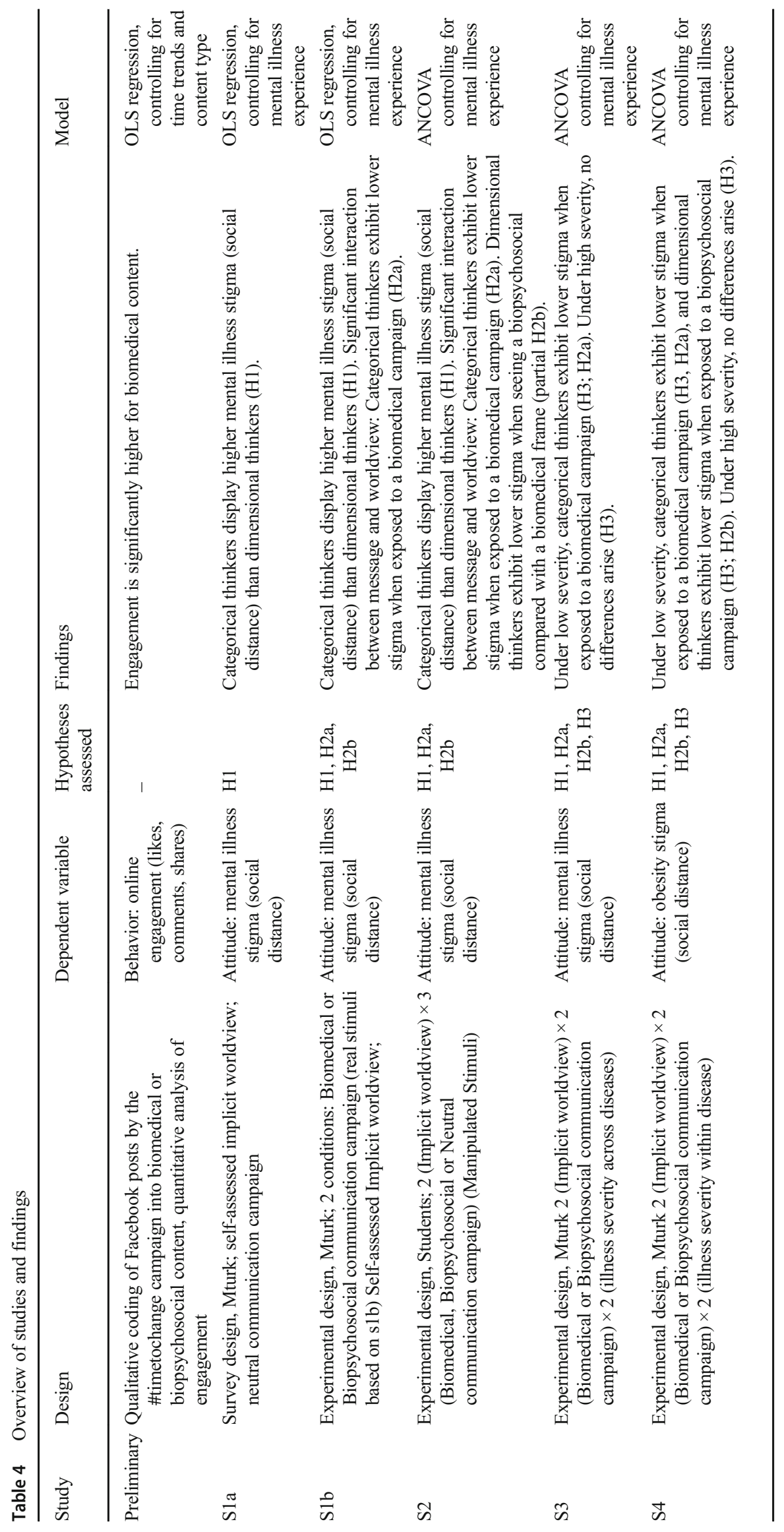


previous experience with mental illness $(\beta=-.280, S E=.055$; $p<.01, r=.36$ ), in line with Lyndon et al. (2016).

\section{Study 1b}

To understand both stigma endorsement and message frame effects, we exposed participants to two exemplars of both frames, drawn from the social media campaign of our preliminary study (Appendix A). These stimuli were validated in the preliminary study, but we also conducted a pilot test to confirm the appropriateness of the stimuli. We measure stigma endorsement and worldview to identify the differential effects of health message frames according to worldview.

Design and procedure To test the differential effects of implicit worldviews on anti-stigma campaigns (H1) and provide initial field-based evidence of the importance of a message frame (H2a and H2b), we exposed 295 U.S.-based MTurk respondents randomly to one of four selected stimuli from the \#TimeToChange campaign, that is, two biopsychosocial stimuli and two biomedical examples (Appendix A) after having assessed their implicit worldview. Respondents were 37 years of age on average, and $45 \%$ of them were men. Moreover, $53 \%$ of respondents had an undergraduate university degree. Similar to the preliminary Study 1a, participants self-assessed their implicit worldview (Dweck et al. 1995), prior to all other measures. An attention check, as in Study 1a, led us to delete 15 responses, for a final sample of 280 respondents.

Dependent measure After seeing the advertisement, respondents completed the social distance measure from Study 1a (Link et al. 1999; Appendix B) to assess their willingness to interact with mentally ill people. We asked demographic questions and assessed familiarity with mental illnesses with the seven-item measure (Schomerus et al. 2007; Appendix B).

Coding and reliability Responses to the implicit theory measure were highly reliable (Cronbach's $\alpha=.91$ ). We calculated the average of the three items to measure participants' chronic implicit worldview; higher values represent more categorical thinking. The stigma measure achieves comparable reliability $\left(\alpha_{\text {SocialDistance }}=.92\right)$ and is coded such that higher scores indicate a more stigmatizing attitude toward mental illnesses.

Pretest To verify the effectiveness of the message frames for the real-life stimuli, we conducted a pretest with 64 respondents from MTurk, using a within-subjects design. All respondents saw all four message stimuli, in combined pairs, such that they rated a biomedical and a biopsychosocial frame in turn, using four semantic differential items (Appendix B). The paired sample t-tests indicate significant differences for each stimulus $\left(M_{\text {Biomed } 1}=3.61, S D=1.23 ; M_{\mathrm{BPS} 1}=4.12, S D=\right.$
$1.06, t_{\text {Biomed } 1-\operatorname{BPS} 1}=-3.21, p<.05, r=.20 ; M_{\text {Biomed } 2}=$ $3.71, S D=1.31, M_{\mathrm{BPS} 2}=4.08, S D=1.20, t_{\mathrm{Biomed} 2}-\mathrm{BPS} 2=$ $-2.70, p<.05, \mathrm{r}=.16$ ).

Results and discussion With an OLS regression (adj. $R^{2}=.13$ ) that controls for familiarity with mental illness, we examined the effect of implicit worldviews on people's mental illness stigma after they have been exposed to either a biomedical or a biopsychosocial message. The main effect of message design on stigma endorsement is non-significant $(\beta=.596, S E=.445$; $p>.1, r=.100$ ), indicating potential moderation. Categorical thinkers demonstrate more stigma than dimensional thinkers, as denoted by the positive coefficient $(\beta=.318, S E=.083$; $p<.01, r=.224)$ and in support of H1. We also observe a significant interaction between message design (biomedical or biopsychosocial) and implicit worldview $(\beta=-.275$, $S E=.123 ; p<.05, r=.141)$. A follow-up Johnson-Neyman spotlight analysis using the mean of the implicit theory scale $\left(M_{\mathrm{IT}}=3.41, S D=1.21\right)$, reveals that for categorical thinkers (at $M_{\mathrm{IT}+} S D=4.62,19 \%$ of respondents are above it) a biomedical frame lowers stigma endorsement, $(\beta=-.673, S E=.210$; $p<.01$ ), while for dimensional thinkers (at $M_{\mathrm{IT}}-S D=2.19$, $21 \%$ of respondents were below it) there is no differential effect of the message frames $(\beta=0.06, S E=.210 ; p>.10)$.

In addition, results of a floodlight analysis indicate that the stigma reducing effect of biomedical frames are effective for respondents who score higher than 3.24 on the implicit worldview scale. This interaction indicates that biomedically framed messages are more effective for reducing stigma among people with stronger categorical mindsets, in support of H2a. However, looking at dimensional thinkers in this study, the campaign messages did not alter their stigma endorsement significantly, so we cannot confirm H2b. Our results are reported in Fig. 1. Mental illness familiarity has a significant influence; lower levels of stigma arise from participants who are more familiar with mental illness $(\beta=-.171, S E=.037 ; p<.01, r=.265$; Lyndon et al. 2016). We next extend these findings using lab-based experiments to provide a stronger test of the hypotheses.

\section{Study 2: Fitting health message frames to implicit worldviews}

We investigate the effects of fitting a message frame with people's implicit worldview to test $\mathrm{H} 2 \mathrm{a}$ and $\mathrm{H} 2 \mathrm{~b}$ in a controlled setting. In addition, we manipulate implicit worldviews instead of using self-reports, to establish causality in the hypothesized effects (Chiu et al. 1997).

\section{Design and procedure}

We set up a 3 (message frame: biomedical vs. biopsychosocial vs. none $) \times 2$ (worldview prime: categorical vs. dimensional) 
Fig. 1 Visualization of the interaction of worldview and message frame (Study 1b). Note: Higher means imply more stigma toward mental illnesses

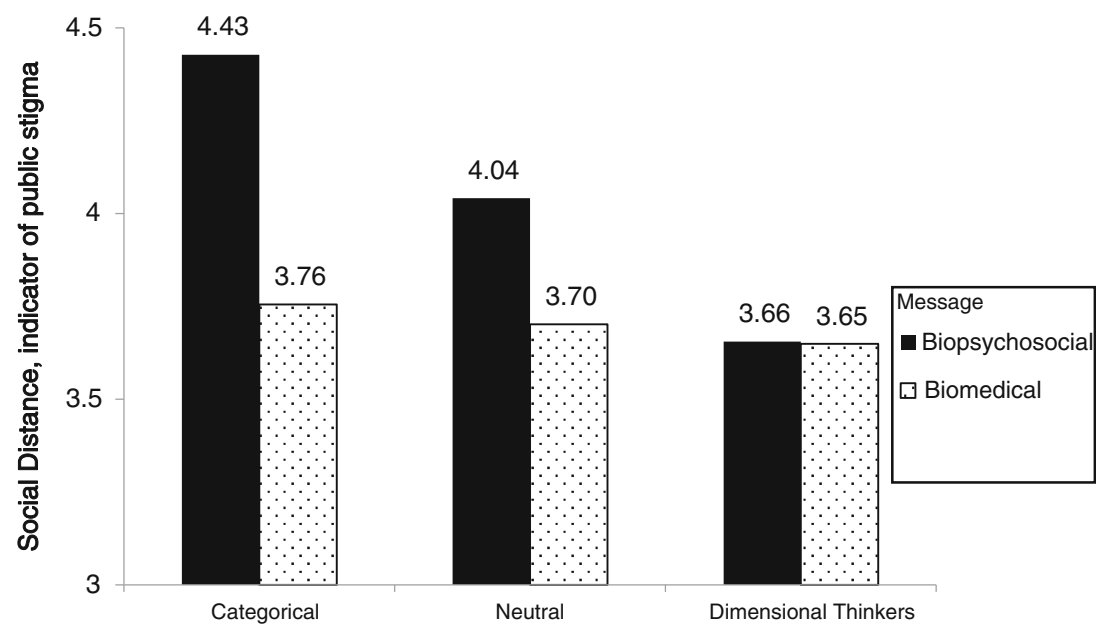

between-subjects experiment. Undergraduate students $(N=$ 250) from a large North American university completed the questionnaire. To ensure that they understood the materials, we included questions to assess the participants' comprehension of the worldview priming materials. Twenty-three participants answered incorrectly, resulting in a final sample of 227 participants. The sample had an average age of 21 years, 55\% were men, and $98 \%$ had a high school diploma as their highest level of completed education.

We manipulated their implicit worldviews at the beginning of the study with a shortened version of the categorical and dimensional worldview prime developed by Chiu et al. (1997), which consists of two versions of an article (see Yorkston et al. 2010). The dimensional prime stressed that people's characters can change over time and supported these statements with examples and scientific evidence. The categorical version instead portrayed basic character traits as fixed over time, citing different examples and academic studies. According to prior studies (Levy et al. 1998; Yorkston et al. 2010), implicit worldviews are a trait-state variable, so people can embrace either worldview, even if they tend chronically to prefer one or the other; that is, both worldviews can be primed.

After the priming and filler questions, participants viewed either the biomedical or the biopsychosocial message about mental illness (Appendix C) or neither; the latter served as the control condition. We then presented the neutral anti-stigma campaign stimuli from Study 1a to all respondents, which helps highlight the relevance of the biomedical and biopsychosocial message frames, in addition to the ad message, and subsequently measured public stigma using the social distance scale (Link et al. 1999). Respondents also noted their personal experience with mental illness.

\section{Results}

Manipulation check The implicit worldview assessment scale, collected at the end of the experiment, served as a successful manipulation check $\left(M_{\text {Dimensional }}=2.82, \mathrm{SD}=.98\right.$; $M_{\text {Categorical }}=3.82, \mathrm{SD}=1.17 ; t(226)=-6.97, p<.001$, $r=.42$ ). We checked the manipulation of the message frame by asking respondents whether they considered mental illnesses static or dynamic and whether mental illnesses are invariant or diverging across cultures, as in the pretest of Study 1b. A significant one-way analysis of variance $(F(2,224)=$ $11.01, p<.001)$ indicated that the definitions successfully altered participants' perceptions of mental illnesses $\left(M_{\text {BioMed }}=\right.$ $2.84, S D=1.10 ; M_{\text {Control }}=3.24, \mathrm{SD}=.94 ; M_{\mathrm{BPS}}=3.63, S D=$ 1.06 , least-square difference post hoc comparisons $p<.05$, $\mathrm{r}=.30)$. The dependent measure is reliable $\left(\alpha_{\text {SocialDistance }}=.91\right)$, and again, higher values indicate more stigmatizing attitudes toward mental illness.

Hypothesis tests To test our hypotheses, we applied an analysis of covariance (ANCOVA), controlling for mental illness familiarity. We find a significant main effect for implicit worldview $(F(1,220)=4.34, p<.05, r=.138)$, which replicates our Study 1 results; categorical thinkers exhibit more stigma. The main effect of the message frame is nonsignificant $(F(2,220)=.76, p>.1)$. Mental illness experience again reveals a significant negative effect $(F(1,220)=15.39$, $p<.01, r=.255$ ), such that stigma levels are lower when people have more experience with mental illness. Finally, the interaction between the message frame and worldview is significant $(F(2,220)=6.64, p<.01, r=.239)$, as we depict in Fig. 2.

Planned contrasts confirm that categorical thinkers exhibit lower stigma when they receive a biomedical rather than a biopsychosocial or no message frame $\left(M_{\mathrm{CatBPS}}=4.32\right.$, $S D=.94 ; M_{\text {CatBioMed }}=3.52, S D=1.04 ; M_{\text {CatCtrl }}=4.06$, $S D=1.35 ; F_{\text {BPS-BioMed }}(1220)=10.29, p<.01 ; F_{\text {BPS }-}$ Control $(1220)=5.51, p<.05)$, in support of H2a. In line with $\mathrm{H} 2 \mathrm{~b}$, dimensional thinkers demonstrate marginally lower stigma when exposed to a biopsychosocial rather than a biomedical message frame, though we find no significant differences 
Fig. 2 Combined effect of message and primed implicit worldviews on stigma (Study 2). Note: Higher means imply more stigma toward mental illnesses

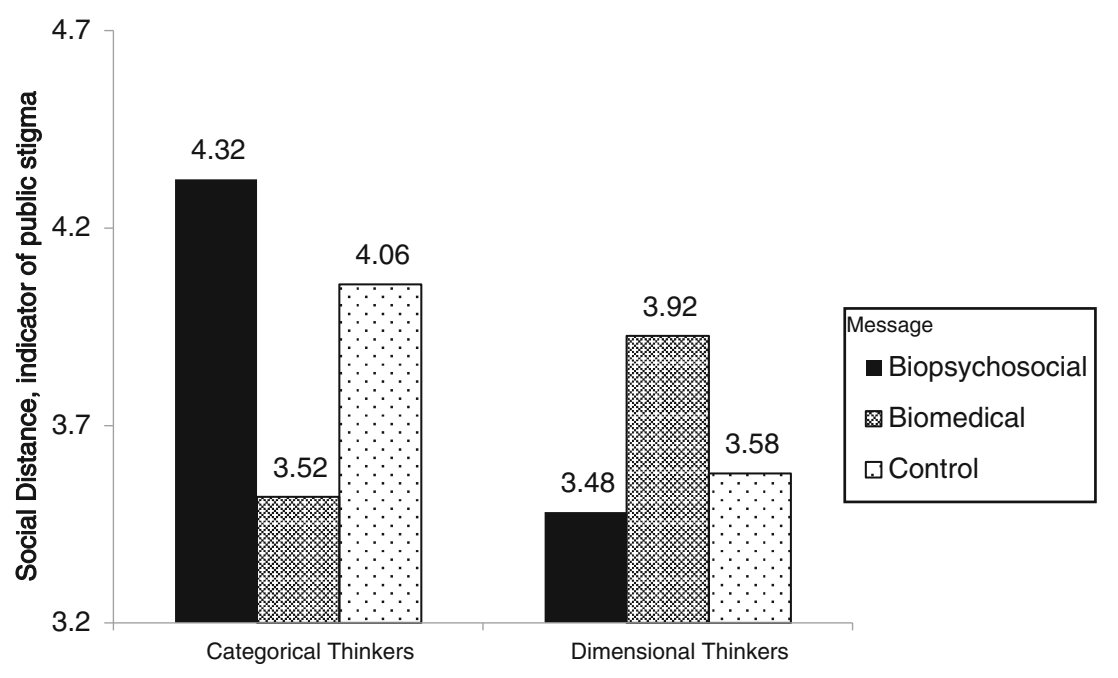

for the control group $\left(M_{\mathrm{DimBPS}}=3.48, S D=1.07\right.$; $M_{\text {DimBioMed }}=3.92, S D=1.24 ; M_{\text {DimCtrl }}=3.58, S D=1.14$; $F_{\text {BPS-BioMed }}(1220)=3.06, p<.1$; all other $\left.p>.1\right)$. Moreover, when exposed to a biopsychosocial or no frame, categorical thinkers exhibit stronger stigma than dimensional thinkers $\left(M_{\mathrm{CatBPS}}=4.32, S D=.94 ; M_{\mathrm{DimBPS}}=3.48, S D=1.07\right.$; $F(1,220)=10.88, p<.01 ; M_{\text {CatCtrl }}=4.06, S D=1.35$; $\left.M_{\text {DimCtrl }}=3.58, S D=1.14 ; F(1,220)=4.02, p<.05\right)$, and this effect reverses marginally when respondents encounter a biomedical frame $\left(M_{\text {CatBioMed }}=3.52, S D=1.04 ; M_{\text {DimBioMed }}=\right.$ 3.92, $S D=1.24 ; F(1,120)=2.81, p<.1)$.

\section{Discussion}

These results indicate that people can be primed to think according to either worldview but also that marketers must consider the fit of the health message frame with the implicit worldview that people hold, if they want to maximize the stigma-reducing capacities of their campaigns. In support of H2a, a biomedical message frame significantly reduces categorical thinkers' stigma, compared with the control group and the biopsychosocial frame. Partially supporting H2b, a mismatch of the message frame and worldview also fails to reduce stigma endorsement, offering some explanation of why anti-stigma campaigns often are ineffective (ArboledaFlórez 2017; Corrigan 2012; Keller and Lehmann 2008).

\section{Study 3: Perceived severity of mental illness as a boundary condition}

We next turn our attention to a potential boundary condition, namely, the perceived severity of mental illness (H3). When mental illnesses are perceived as low in severity, more ambiguity exists (cf. severe illness) regarding whether a person can be diagnosed with the illness, due to the relatively limited impairments to her or his daily functioning. As we have established already, categorical thinkers may exhibit greater stigma in response to a biopsychosocial message but not a biomedical message, and dimensional thinkers instead should be more persuaded by a nuanced biopsychosocial message than by the biomedical perspective ( $\mathrm{H} 2 \mathrm{a}$ and $\mathrm{H} 2 \mathrm{~b})$. Here, we also argue that when perceived illness severity is high, the stigma differences between worldviews get attenuated.

\section{Design and procedure}

We use a 2 (message frame: biomedical vs. biopsychosocial) $\times$ 2 (worldview prime: categorical vs. dimensional) $\times 2$ (perceived illness severity: low vs. high) between-subjects experimental design. Respondents $(N=326)$ from MTurk completed the questionnaire, but we removed 10 participants that indicated their lack of seriousness on the check that we also used in Study 1. Another 34 respondents were excluded because they failed the implicit worldview prime comprehension checks from Study 2, yielding a final sample of 282 participants. The final sample had an average age of 33 years (18 to 69 years), 99\% were U.S. citizens, and 56\% were men. Finally, $23 \%$ of the respondents finished high school, another $21 \%$ had completed an apprenticeship or additional training, and $56 \%$ held a college degree. These participants were randomly exposed to the categorical or dimensional worldview primes from Study 2 (Chiu et al. 1997), then received either the biomedical or biopsychosocial message (Appendix C). Participants reviewed advertisements focused on either Internet addiction (low severity) or schizophrenia (high severity; Appendix A).

\section{Results}

Pretest To select mental illness conditions for the study, we pretested a list of eight mental illnesses with regard to their perceived severity, using a three-item scale developed by 
Witte (1996). Internet addiction, which falls within the family of impulse control disorders (WHO 2013), was perceived as the least severe, statistically equal to the neutral scale midpoint $\left(M_{\text {Int }}=4.38, S D=1.65 ; t(31)=1.31, p>.1\right)$. Schizophrenia was perceived as the most severe $\left(M_{\text {Schiz }}=6.33, S D=1.49\right)$ and significantly more severe than Internet addiction $(t(31)=$ $7.21, p<.01, r=.46)$. The mean mental illness severity across the eight mental illnesses was significantly higher than Internet addiction but significantly lower than schizophrenia $\left(M_{\text {Mental }}=5.26, S D=1.74, t_{\text {Int-Mental }}(31)=4.64, p<.01\right.$, $\left.r=.35 ; \mathrm{t}_{\text {Mental-Schiz }}=4.59, p<.01, r=.33\right)$.

Manipulation check Similar to Study 2, we included the implicit worldview assessment scale at the end of the experiment to serve as a manipulation check. The results indicate that worldview was successfully manipulated $\left(M_{\text {Dimensional }}=\right.$ 2.86, $S D=1.04 ; M_{\text {Categorical }}=3.74, S D=1.19 ; t(280)=6.30$, $p<.001, r=.37)$.

Hypothesis tests In an ANCOVA in which we controlled for mental illness experience, we find a marginally significant three-way interaction of implicit worldview $\times$ message $\times$ illness severity $(F(1,273)=3.37, p=.068, r=.110)$. All other main and interaction effects are non-significant, except for the control variable, such that stigma decreases with more mental illness experience $(F(1,273)=12.01, p<.01, r=.205)$.

To test $\mathrm{H} 3$, we report planned contrasts to investigate the worldview $\times$ message frame interaction at low or high levels of perceived mental illness severity. The results for low perceived severity largely replicate our findings from Study 2 . In partial support of $\mathrm{H} 3$, when perceived mental illness severity is low, categorical thinkers exposed to a biomedical frame express significantly lower stigma than those exposed to a biopsychosocial frame $\left(M_{\text {CatBioMed }}=3.75, S D=1.29 ; M_{\text {CatBPS }}=4.39, S D=1.12\right.$; $F(1,273)=4.42, p<.05)$. Dimensional thinkers indicate equivalent attitudes across message frames $\left(M_{\text {DimBioMed }}=3.93, S D=\right.$ $\left.1.31 ; M_{\text {DimBPS }}=3.70, S D=1.27 ; F(1,273)=.59, p>.1\right)$. When perceived mental illness severity is high, the planned contrasts reveal no significant differences across conditions, as we predicted in H3 $\left(M_{\text {DimBPS }}=3.89, S D=1.29 ; M_{\text {DimBioMed }}=3.93, S D=\right.$ $1.44 ; M_{\text {CatBPS }}=3.74, S D=1.58 ; M_{\text {CatBioMed }}=4.00, S D=1.18$; all $p>.1$; see Fig. 3).

\section{Discussion}

These results offer further, if partial, support for our prediction that when mental illness is perceived as less severe, matching a biomedical (biopsychosocial) message frame with categorical (dynamic) theorists' worldview lowers stigma. That is, we confirm this prediction for categorical thinkers (H2a) but find no significant result for dimensional thinkers $(\mathrm{H} 2 \mathrm{~b})$ - though the observed means trend in the expected direction. Furthermore, our results confirm the attenuation of these effects when perceived illness severity is high. Thus, Study 3 partially supports our previous findings and establishes perceived illness severity as an important boundary condition. As long as anti-stigma campaigns are general in their domain (e.g., "mental illness") or focused on low severity illnesses, messages should match their biomedical or biopsychosocial approaches to recipients' implicit worldviews. If the campaign instead focuses on a severe mental illness, the differences between the two implicit worldviews are less relevant.

\section{Study 4: Within-illness severity and extension to obesity-related stigma}

We seek to substantiate and generalize our previous findings by shifting the study context to test $\mathrm{H} 2 \mathrm{a}, \mathrm{H} 2 \mathrm{~b}$, and $\mathrm{H} 3$ again. Study 3 tested illness severity as a between-condition phenomenon; in Study 4 , we tackle the perceived severity of the same condition. In addition, mental illness is not the only healthcare field in which public stigma is a major obstacle to people seeking treatment. Thus, to determine if our findings transfer to physical health conditions, we focus on obesity in Study 4.

\section{Design and procedure}

The design of Study 4 is a 2 (message frame: biomedical vs. biopsychosocial) $\times 2$ (worldview prime: categorical vs. dimensional $) \times 2$ (perceived illness severity: low vs. high) between-subjects experiment. Of the 300 respondents from MTurk who completed the study, 46 were removed due to self-reported lack of seriousness (12) or a failed reading comprehension score (34). The final sample, with 254 participants, had an average age of 34 years (18 to 71 years), $61 \%$ were men, the majority indicated a college degree as their highest form of education (56\%), and 99\% were U.S. citizens. Participants were randomly allocated to read the categorical or dimensional prime, as in Studies 2 and 3, then received a biomedical or biopsychosocial message about obesity, followed by a low or high severity presentation of obesity (Appendix C), using different symptoms that we pretested. Then participants were exposed to a neutral anti-stigma campaign focused on obesity (Appendix A). They completed the measures of interest, manipulation checks, and demographic items.

\section{Results}

Manipulation check As in previous studies, we tested the manipulation of worldviews, which proved successful $\left(M_{\text {Dimensional }}=3.19, S D=1.36 ; M_{\text {Categorical }}=3.83, S D=1.43\right.$; $t(252)=-3.61, p<.001, r=.22)$. We also tested the message frame manipulation, using the items from Study 2; the frame significantly altered perceptions of the variability of causes of obesity $\left(\mathrm{M}_{\text {Biomed }}=3.11, S D=1.07 ; M_{\mathrm{BPS}}=3.62, \mathrm{SD}=1.01\right.$, 
Fig. 3 Implicit worldview $x$ message interaction for high and low illness severity (Study 3 ). Note: Higher means imply more stigma toward mental illnesses

\section{Low Perceived Illness Severity}

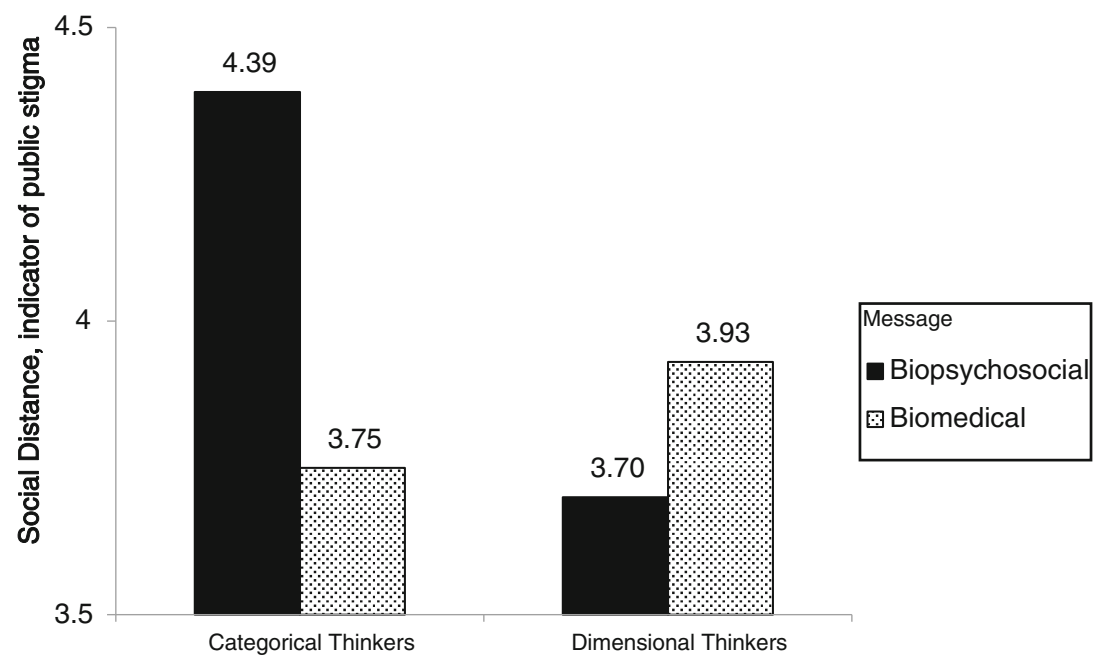

High Perceived Illness Severity

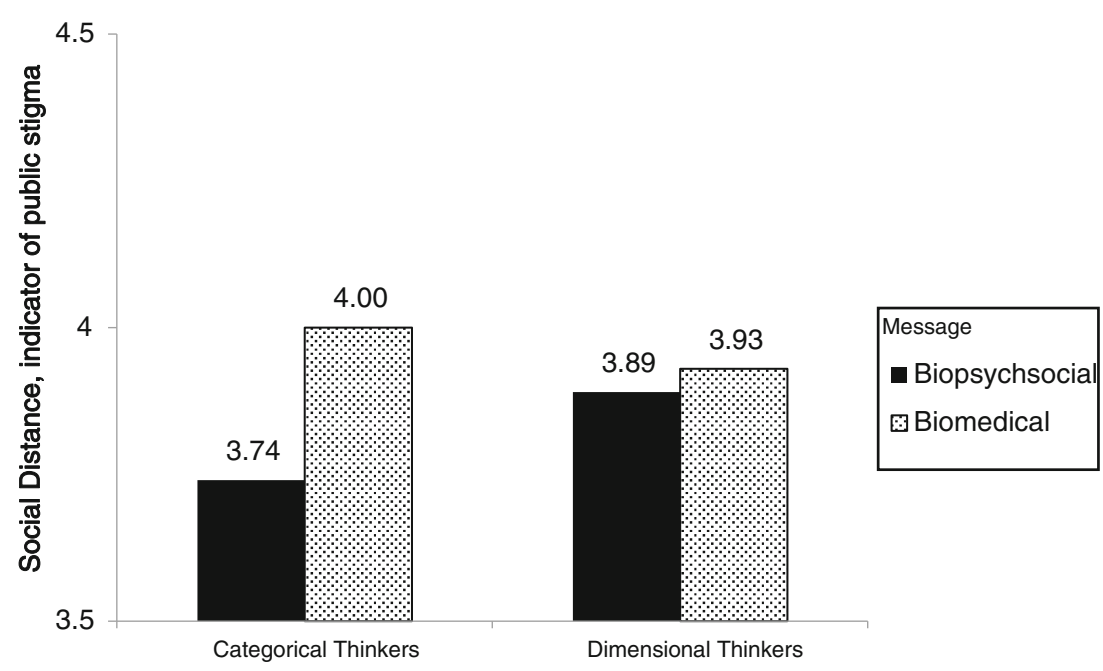

$t(252)=-3.82, p<.001, r=.23)$. Finally, we tested the severity manipulation using the items from the pretest of Study 3 and found a significant shift in the perceived severity of obesity $\left(\mathrm{M}_{\text {Mild }}=5.17, S D=1.16 ; M_{\text {Severe }}=5.76, \mathrm{SD}=1.00, t(252)=\right.$ $-4.26, p<.001, r=.26)$.

Hypothesis tests A significant ANCOVA $(F(8,245)=2.35$, $p<.05, \mathrm{r}=.26$ ), controlling for obesity experience, demonstrates a significant two-way interaction between implicit worldview and message frame $(F(1,245)=4.90, p<.05$, $r=.141)$, as well as a significant three-way interaction of implicit worldview $\times$ message frame $\times$ illness severity $(F(1$, $245)=4.58, p<.05, r=.134)$. We controlled for experience with the condition (obesity), which proves significant $(F(1,245)=7.12, p<.01, r=.167)$, indicating less stigma with more experience with this condition. All other main and interaction effects are non-significant.
To confirm that $\mathrm{H} 3$ holds for within-illness changes of perceived severity in a physical health context, we analyze the worldview $\times$ message interaction separately for low and high perceived severity. When perceived severity is low, the results largely support our previous findings. When categorical thinkers are exposed to the biomedical, rather than biopsychosocial, frame, they indicate significantly lower stigma $\left(M_{\mathrm{CatBioMed}}=2.31\right.$, $\mathrm{SD}=1.36 ; M_{\text {CatBPS }}=3.06, S D=1.43 ; F(1,245)=6.39$, $p<.05, r=.159)$. In further support of $\mathrm{H}_{3}$, dimensional thinkers respond with less obesity stigma to a biopsychosocial frame than a biomedical one $\left(M_{\text {DimBPS }}=2.41, S D=1.05 ; \mathrm{M}_{\text {DimBioMed }}=3.06, \mathrm{SD}=\right.$ $1.19 ; F(1,245)=4.50, p<.05, r=.134)$. The worldview $\times$ message interaction is non-significant in the high severity condition, in support of $\mathrm{H}_{3} \quad\left(M_{\mathrm{DimBPS}}=2.72\right.$, $S D=.94 ; M_{\text {DimBioMed }}=2.61, S D=1.19 ; M_{\text {CatBPS }}=2.74$, 
Fig. 4 Implicit worldview $x$ message interaction for high and low obesity severity (Study 4). Note: Higher means imply a more stigma toward obesity
Low Perceived Obesity Severity

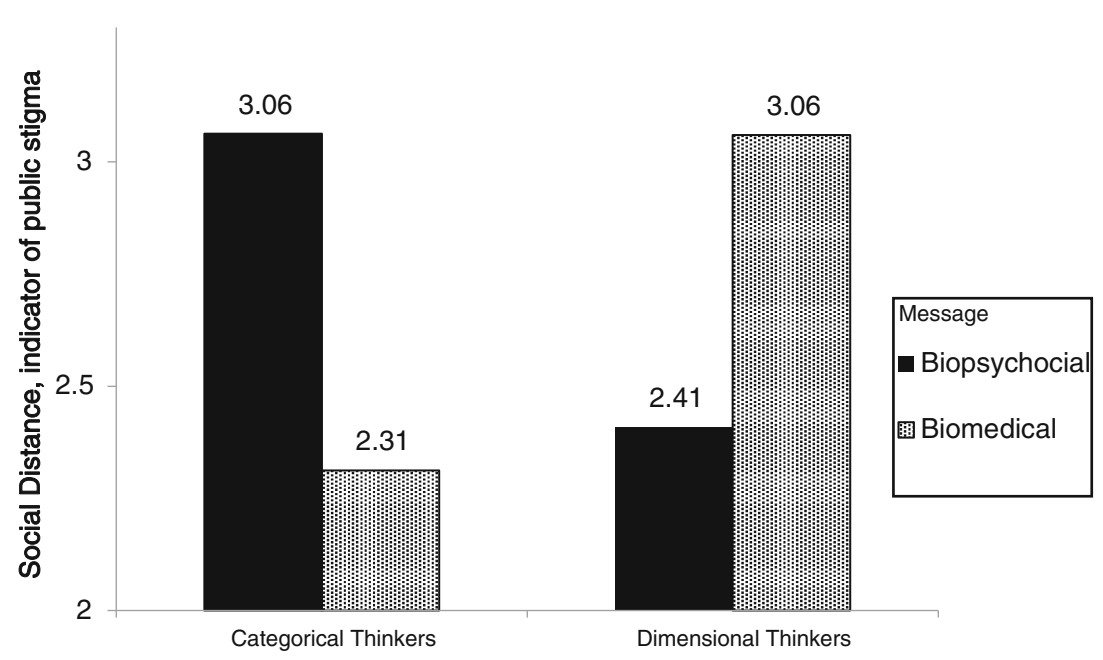

High Perceived Obesity Severity

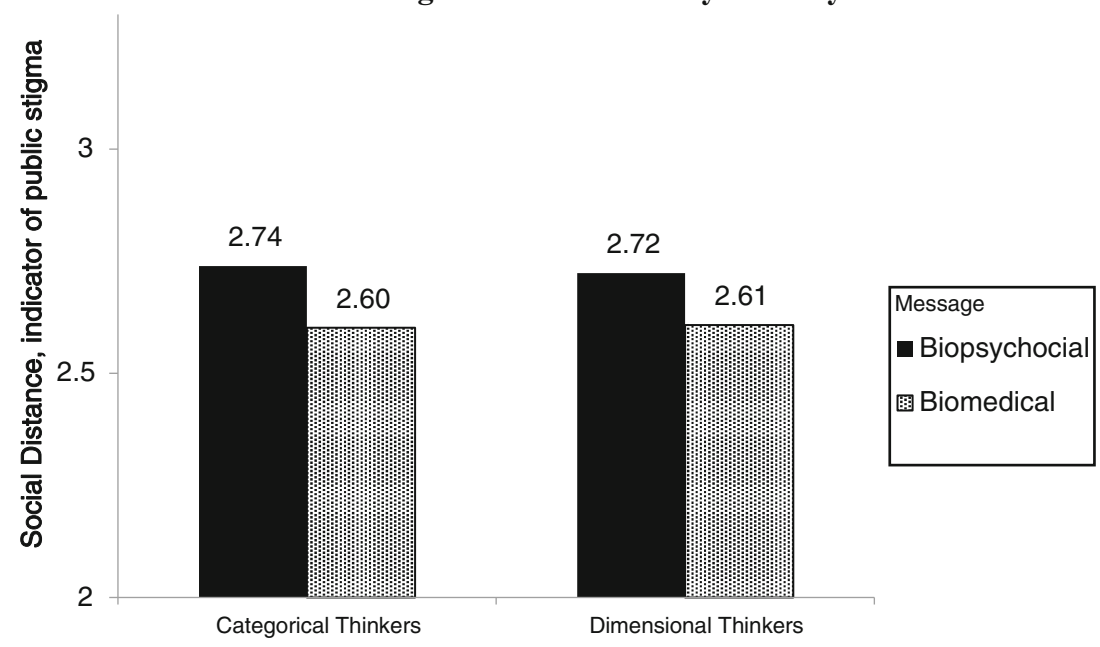

$S D=1.34 ; M_{\text {CatBioMed }}=2.60, S D=1.10 ;$ all $p>.1$; Fig. 4). When illness severity is perceived as high, categorical and dimensional thinkers exhibit equal levels of stigma in response to both biomedical and biopsychosocial frames.

\section{Discussion}

This study deepens understanding of how to reduce public stigma by confirming that matching the frame used to describe an illness with recipients' worldview affects public stigma in physical disease categories, such as obesity ( $\mathrm{H} 2 \mathrm{a}$ and $\mathrm{H} 2 \mathrm{~b})$. We also replicate the findings of a moderating role of high illness severity perceptions on the interaction of worldviews and message frames (H3). These results are a promising step toward a new approach for public stigma campaigns.

\section{General discussion}

The burden of mental illnesses is evident at both personal and societal levels (WHO 2013). Substantial ongoing work at the individual level seeks effective ways to overcome the socalled treatment gap, such that only $25 \%-30 \%$ of people with mental illnesses receive treatment (WHO 2017a). Our focus is on public mental illness stigma, which significantly impedes both the effectiveness of individual-level campaigns and the potential societal benefits associated with addressing mental illnesses. Combating public stigma is a critical component of efforts to reduce the burdens of mental illness at all levels (Corrigan 2004). Yet campaigns aimed at reducing public stigma (Table 1) remain only marginally effective, which might be because they lack theoretical evidence and guidelines for developing effective designs. Social marketers have unique expertise in this realm and can make a meaningful 
impact. With our novel perspective on public stigma, we seek to offer substantive, theoretically informed insights on how managers can increase the stigma reduction of their campaigns by customizing their health messaging to match receivers' implicit worldviews.

We also conducted a meta-analysis of the effects from our four studies. Our results indicate significant support for each hypothesis. The file drawer statistics, which indicate how many null effect size values would be needed to reduce the overall significance levels to .05 are also reported (Table 5). These results engender greater confidence in the overall results.

\section{Implications for theory}

This study contributes to social marketing literature in several ways. We extend research on implicit worldviews and identify them as important predictors of public stigma towards various disease categories. We demonstrate that people's implicit worldviews of human character traits (categorical or dimensional) strongly determine the level of stigma they express (Lyndon et al. 2016). Categorical thinkers display more stigma on average. This finding helps explain some variability in public stigma, as well as why anti-stigma campaigns might fail to achieve their desired results. That is, they fail to consider and customize the content of the message to match receivers' implicit worldviews. Nor are these insights restricted to mental illnesses; we empirically demonstrate their relevance for physical health conditions too.

In turn, we demonstrate that matching recipients' implicit worldviews with the message frame used to describe mental illness is a promising way to lower public stigma. Previous studies recommend priming categorical thinkers to take a dimensional worldview to reduce stigma (e.g., Plaks et al. 2001; Yorkston et al. 2010). We replicate these findings in Studies $2-4$ but also extend prior insights by integrating implicit worldviews with two illness frames: biopsychosocial (Kiesler 1999) and biomedical (Guze 1992). As a contribution to research into the interaction of message frames and personality traits, we demonstrate the benefits of matching message frames with implicit worldviews. Specifically, we show that categorical thinkers prefer a biomedical frame with less ambiguity, but dimensional thinkers tend to prefer a more nuanced, biopsychosocial frame that contains more ambiguity. The effect of framing is reduced for dimensional thinkers, which is likely a result of their more fine-grained thinking about mental illness. As a caveat, perceived illness severity serves as a boundary condition. The effect of matching the message frame and worldview holds for mental illnesses and physical health conditions perceived as less severe but not for those perceived as more severe.

This study is also the first to demonstrate a significant reduction in stigma among categorical thinkers, simply due to the application of a biomedical message frame. Dimensional thinkers express higher public stigma after being exposed to a biomedical frame, a finding that offers further support for the prediction that violating worldviews can alter perceptions.

\section{Implications for policymakers and managers}

This study offers several insights for marketing managers and policymakers. We shed light on why social marketing campaigns aiming to reduce public stigma often yield mixed results. If public stigma campaigns do not adopt an appropriate biomedical or biopsychosocial frame, they likely fail to achieve the desired effect (lower public stigma). Our field evidence also implies an underuse of biomedical messages, considering the greater levels of engagement they can produce. They align well with categorical thinkers' worldview, and categorical thinkers are relevant targets for public stigma campaigns, due to their higher level of stigma endorsement. Mismatching message frames with worldviews can even lead to higher stigma levels, so it is critical for social marketing managers to achieve a match. We suggest increased uses of both biomedical messages and

Table 5 Meta-analysis of the proposed effects

\begin{tabular}{|c|c|c|c|c|c|c|c|}
\hline Hypothesis & Description & $\begin{array}{l}\text { \# of } \\
\text { effects }\end{array}$ & $\begin{array}{l}\text { Mean } \\
\text { effect }\end{array}$ & $\begin{array}{l}\text { CI } \\
\text { (Lower) }\end{array}$ & $\begin{array}{l}\text { CI } \\
\text { (Upper) }\end{array}$ & $\begin{array}{l}\mathrm{Z} \text { - } \\
\text { value }\end{array}$ & $\begin{array}{l}\text { File } \\
\text { drawer }\end{array}$ \\
\hline 1 & $\begin{array}{l}\text { Categorical thinkers exhibit more public stigma, measured by social distance, than dimensional } \\
\text { thinkers after both groups have been exposed to counter-stigmatic information. }\end{array}$ & 5 & $0.117 * *$ & 0.061 & 0.169 & 2.852 & 18 \\
\hline $2 \mathrm{a}$ & $\begin{array}{l}\text { Categorical thinkers exhibit lower levels of public stigma, measured by social distance, after } \\
\text { being exposed to a biomedical frame message rather than a biopsychosocial frame message. }\end{array}$ & 3 & $0.308 * * *$ & 0.165 & 0.438 & 4 & 29 \\
\hline $2 b$ & $\begin{array}{l}\text { Dimensional thinkers exhibit higher levels of public stigma, measured by social distance, after } \\
\text { being exposed to a biomedical frame message rather than a biopsychosocial frame }\end{array}$ & 3 & $0.131 * *$ & 0.033 & 0.226 & 3 & 3 \\
\hline 3 & $\begin{array}{l}\text { When illness is perceived as low in severity, a biomedical (biopsychosocial) message frame } \\
\text { presented to categorical (dimensional) thinkers reduces stigma endorsement in comparison } \\
\text { with a biopsychosocial (biomedical) message. This effect is attenuated for illnesses perceived } \\
\text { as severe. }\end{array}$ & 2 & $0.121 * *$ & 0.039 & 0.2 & 3 & $\mathrm{n} / \mathrm{a}$ \\
\hline
\end{tabular}

Random effects model used. $* p<.10, * * p<.05$, *** $p<.01$ 
social media channels to support customization. On social media, messages can be personalized to each user, and data mining tools likely can classify users as categorical or dimensional thinkers. Another option would be to combine appropriate worldview primes with the applied message frame to reduce stigma; the prime helps ensure message effectiveness. However, such priming must be performed with care.

Managers should consider the focus of their campaigns. Our results hold for mental and physical conditions perceived as less severe. However, not all campaigns are as general as the examples we used. Some specific campaigns seek to combat stigma associated with particular diseases, such as depression or schizophrenia (Rochlen et al. 2005). In these cases, managers should manipulate the perceived severity of the condition and leverage matching effects to lower public stigma. Existing perceptions of illness severity among the audience should be assessed prior to the launch of any campaign. For diagnoses that people perceive as severe, the choice between a biomedical and a biopsychosocial frame is less important. In turn, we propose that campaigns might first seek to increase understanding of the severity of the health concern before initiating efforts to achieve public stigma reduction; that is, a phased approach may be necessary.

\section{Limitations and avenues for research}

Our social media field data cover a 52-week period, but the laboratory and online panel settings are cross-sectional. Further research should replicate the reported effects with a longitudinal field study. We demonstrate that it is possible to reduce public stigma by matching message frames with implicit worldviews in health-related conditions. Continued research could test whether our findings generalize to other stig- matization settings, such as racial and gender-related biases, in accordance with the sustainable development goals set by the United Nations (2018). In a similar vein, it would be interesting to investigate how implicit worldviews interact with other interpersonal differences, such as regulatory focus, that are relevant in health decisions (Bhargave et al. 2015). Different message frames might interact with implicit worldviews too; for example, campaigns that emphasize greater perceived controllability or treatability may alter the public stigma expressed by categorical and dimensional thinkers. The phenomenon of normalization might be considered too. Reduced public stigma typically makes certain actions more accepted, an outcome that should benefit people with mental illnesses and encourage them to seek help, but it may be detrimental to people diagnosed with obesity, in that they might reduce their efforts to eat healthier foods or exercise more (Lin and McFerran 2016).

Finally, our results pertain to public stigma, not the self-stigma perceived by affected people. Researchers could investigate whether our results extend to behavioral intentions such as seeking and completing treatment; many people diagnosed with mental illnesses never complete or even refuse to start treatment, due to fears of stigmatization (WHO 2010). Anecdotal evidence and qualitative research both indicate that the success rates of treatment programs tend to be higher if they match patients' worldviews (Tranulis et al. 2014). Perhaps people who endorse an implicit worldview are more likely to adhere to a treatment plan that adopts an appropriately matched biomedical or biopsychosocial approach. Such patient-centered treatment, informed by multidisciplinary evidence, may improve mental and physical health treatments and ultimately enhance the public good.

\section{Appendix 1: Stimuli}

\section{Study 1a/Study 2, Neutral Advertisement}

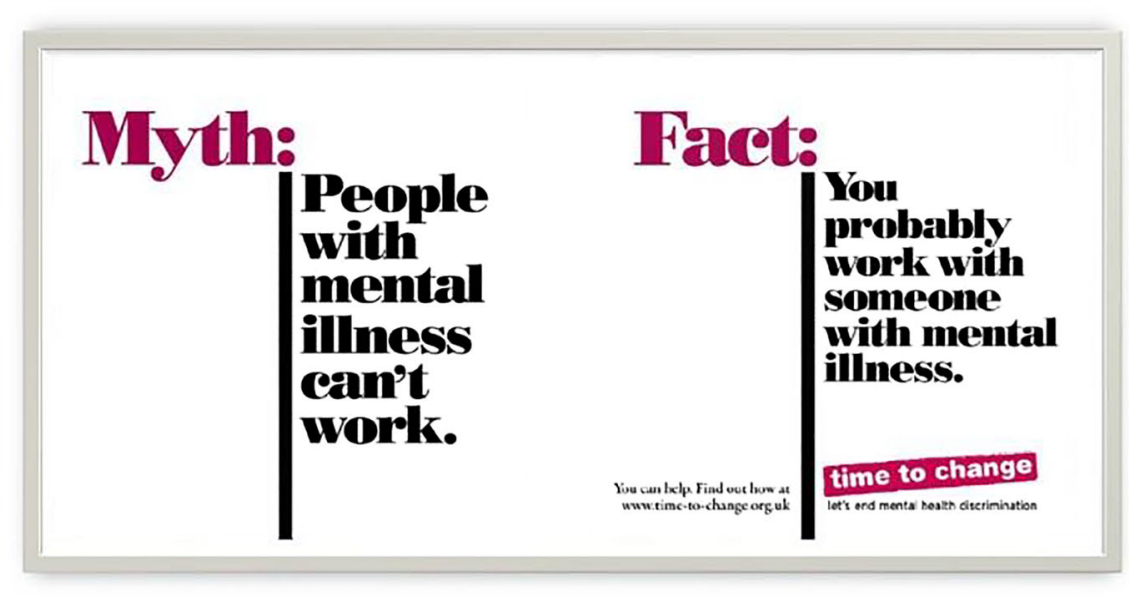


Study 1b, Sample Biomedical Sample Ad

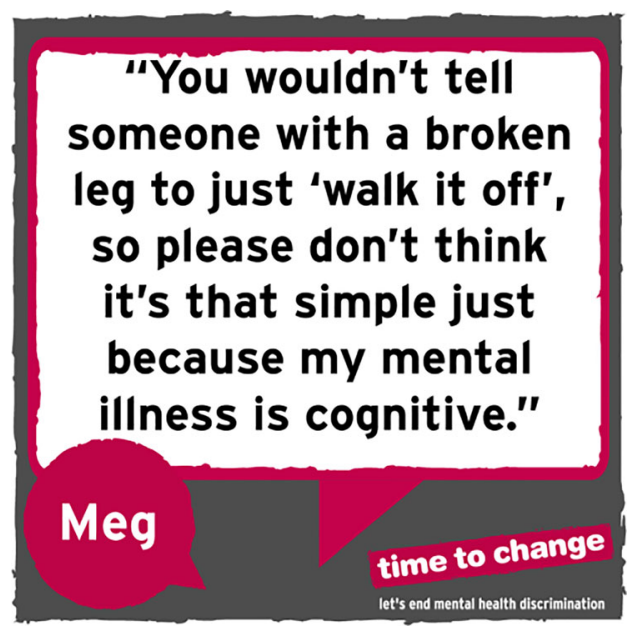

Study 1b, Sample Biopsychosocial Sample Ad

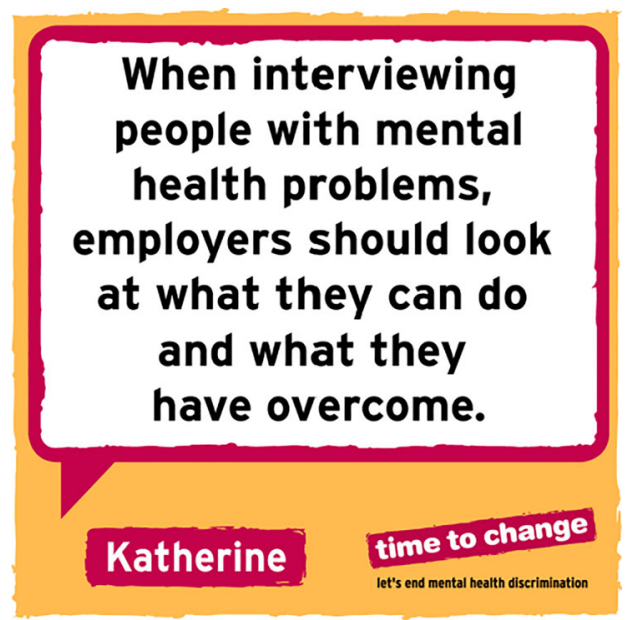


Study 3, Advertisements with Different Degrees of Illness Severity
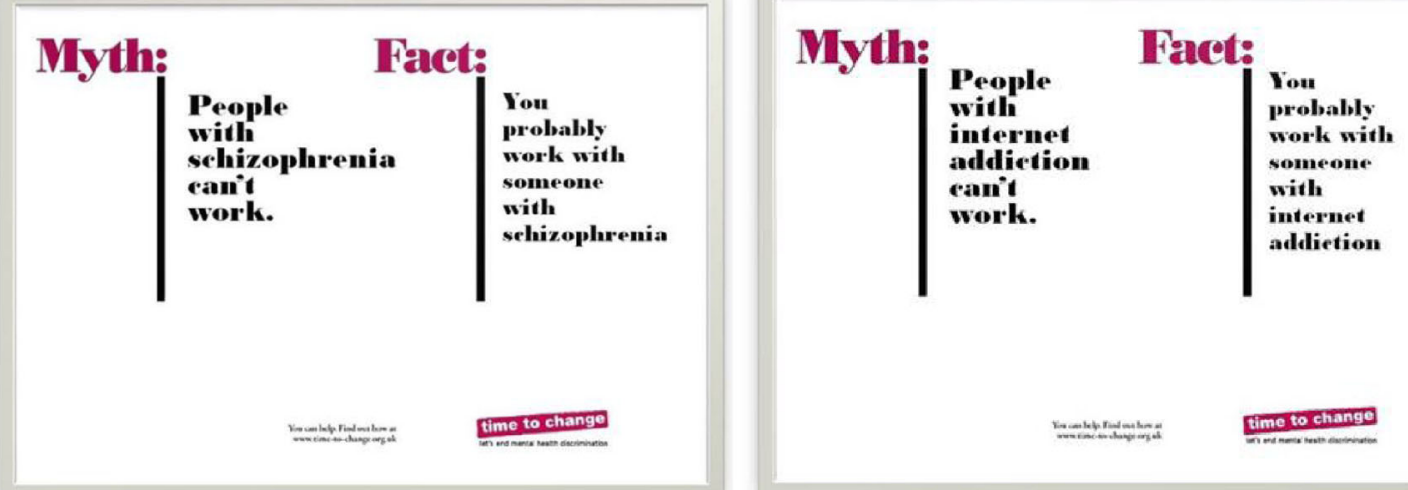

\section{Study 4, Neutral Obesity Advertisement}

\section{Appendix 2: Scales}

Implicit worldviews (Dweck et al. 1995) ( $\alpha$ values: study $1 \mathrm{a}=.85$, Study $1 \mathrm{~b}=.92$ ),

Point scale, anchors: Strongly disagree, strongly agree

1. The kind of person someone is, is something basic about them, and it can't be changed very much.

\section{Fact:}

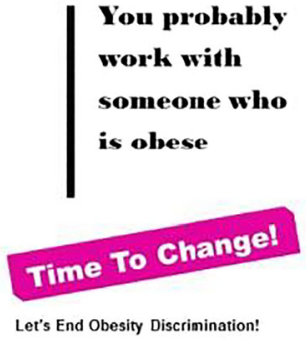

2. People can do things differently, but the important parts of who they are can't really be changed.

3. Everyone is a certain kind of person, and there's not much that they can do to really change that.

Social distance items (Link et al. 1999) ( $\alpha$ values: Study $1 \mathrm{a}=.84$, Study $1 \mathrm{~b}=.91$, Study $2=.91$, Study $3=.92$, Study $4=.91)$. 
Point scale, anchors: Definitely willing, definitely unwilling

1. How would you feel about renting a room in your home to someone with a mental illness?

2. How would you feel as a worker on the same job as someone with a mental illness?

3. How would you feel having someone with a mental illness as a neighbor?

4. How about a person with a mental illness as the caretaker of your children for a couple of hours?

5. How about having your children marry someone with a mental illness?

6. How would you feel about introducing a person with a mental illness to a young woman you are friendly with?

7. How would you feel about recommending someone with a mental illness for a job working for a friend of yours?

Familiarity with mental illnesses (Schomerus et al. 2007) (formative scale, no $\alpha$ values, summed to create an index).

Which of the following situations did you experience? (yes/no)

1. I have had a job/study which involved providing services or treatment or persons with mental illness.

2. I have observed, in passing, a person I believe may have had a severe mental illness.

3. I have observed persons with a severe mental illness on a frequent basis.

4. I have worked with a person who had a severe mental illness at my place of employment.

5. A friend of the family has a severe mental illness.

6. I have a relative who has a severe mental illness.

7. I live with a person who has a severe mental illness.

Mental illness perception 7-point scale, Semantic Differential:

According to the above message, mental conditions are:

1. Diagnosable categories vs. Individual conditions

2. Like physical conditions vs. Different from physical conditions

3. Medical conditions vs. An interplay of psychological, social and biological factors

4. Caused only by biological dysfunction vs. Caused by a complex interplay of personal experiences, family dynamics, and biological dysfunctions

Illness severity (Witte 1996) ( $\alpha$ value Internet Addiction: .90; Schizophrenia: .97; Mental Illness: .96).

7 point scale, anchors strongly disagree, strongly agree I believe that (Condition) is:
1. Severe

2. Significant

3. Serious

\section{Appendix 3: Definitions Provided to Respondents in Study 2, 3 and 4}

\section{Study 2 \&3}

Biomedical: "Because mental illness is caused by biological dysfunctions, it can be often diagnosed as a clear-cut disease category, just like physical illness. This also means that individuals with the same mental illness display a similar set of symptoms even across cultures and over time."

Biopsychosocial: "Because mental illnesses are caused by a complex interplay of personal experiences, family dynamics, and biological dysfunctions, they are unique for each individual person. This means that individuals with the same mental illness display varying symptoms that can differ across cultures and over time."

\section{Study 4}

Biomedical, Obesity: "Obesity is often caused by biological dysfunctions such as genetic mutations. This means that the causes of obesity are similar across cultures and over time making them static and generalizable."

Biopsychosocial, Obesity: "Obesity is often caused by a complex interplay of psychological, social and biological dysfunctions. This means that the causes of obesity vary across cultures and over time making them dynamic and individual."

Obesity Severity Manipulation: "Obesity is relatively a minor disease, as it is can cause arthritis, digestive problems and diabetes."

"Obesity is relatively a very serious disease, as it is can cause cancer, stroke, and depression."

Open Access This article is distributed under the terms of the Creative Commons Attribution 4.0 International License (http:// creativecommons.org/licenses/by/4.0/), which permits unrestricted use, distribution, and reproduction in any medium, provided you give appropriate credit to the original author(s) and the source, provide a link to the Creative Commons license, and indicate if changes were made.

\section{References}

Adnsager, J., Austin, E., \& Pinkleton, B. (2001). Questioning the value of realism: Young adults' processing of messages in alcohol-related public service announcements and advertising. Journal of Communication, 51(1), 121-142. 
Ambrose, D. (2017). Avoiding dogmatic traps in creativity and education through awareness of worldviews and visual metaphor. In Creative contradictions in education (pp. 55-73). Switzerland: Springer International Publishing.

Andreasen, A. R., Goodstein, R. C., \& Wilson, J. C. (2005). Transferring "marketing knowledge" to the nonprofit sector. California Management Review, 47(4), 46-67.

Arboleda-Flórez, J. (2017). What has not been effective in reducing stigma. In W. Gaebel, W. Rossler, \& N. Sartorius (Eds.), The stigma of mental illness-end of the story? (pp. 515-530). Switzerland: Springer International Publishing.

Bastian, B., \& Haslam, N. (2006). Psychological essentialism and stereotype endorsement. Journal of Experimental Social Psychology, $42(2), 228-235$.

Berger, J. (2011). Arousal increases social transmission of information. Psychological Science, 22(7), 891-893.

Bhargave, R., Chakravarti, A., \& Guha, A. (2015). Two-stage decisions increase preference for hedonic options. Organizational Behavior and Human Decision Processes, 130, 123-135.

Booth, R. (2017). Royals launch campaign to get Britons talking about mental health. Retrieved on February 28, 2019 from: https://www. theguardian.com/society/2017/mar/29/royals-launch-mental-healthcampaign-videos-get-britons-talking. Accessed 28 Feb 2019

Bresnahan, M. J., Silk, K., \& Zhuang, J. (2013). You did this to yourself! Stigma and blame in lung cancer. Journal of Applied Social Psychology, 43, E132-E140.

Byrne, P. (2000). Stigma of mental illness and ways of diminishing it. Advances in Psychiatric Treatment, 6(1), 65-72.

Chiu, C. Y., Hong, Y., \& Dweck, C. S. (1997). Lay dispositionism and implicit theories of personality. Journal of Personality and Social Psychology, 73, 19-30.

Chandran, S., \& Menon, G. (2004). When a day means more than a year: Effects of temporal framing on judgments of health risk. Journal of Consumer Research, 31(2), 375-389.

Coffey, R.M., Houchens R., Chu, B., Kassed C., Owens, P., Stocks, C., Vandivort-Warren, R., \& Barrett, M.L. (2011). A severity-of-illness classification for mental and substance-use-disorders for use with hospital administrative data. Rockville, MD: Healthcare cost and utilization project (HCUP).

Corrigan, P. (2004). How stigma interferes with mental health. American Psychologist, 59(7), 614-627.

Corrigan, P. (2012). Where is the evidence supporting public service announcements to eliminate mental illness stigma? Psychiatric Services, 63(1), 79-82.

Corrigan, P. W., Green, A., Lundin, R., Kubiak, M. A., \& Penn, D. L. (2001). Familiarity with and social distance from people who have serious mental illness. Psychiatric Services, 52(7), 953-958.

Corrigan, P. W., Morris, S. B., Michaels, P. J., Rafacz, J. D., \& Rusch, N. (2012). Challenging the public stigma of mental illness: A metaanalysis of outcome studies. Psychiatric Services, 63(10), 963-973.

Crisp, A., Gelder, M., Goddard, E., \& Meltzer, H. (2005). Stigmatization of people with mental illnesses: A follow-up study within the changing minds campaign of the Royal College of psychiatrists. World Psychiatry, 4(2), 106-113.

Daryanto, A., de Ruyter, K., Wetzels, M., \& Patterson, P. G. (2010). Service firms and customer loyalty programs: A regulatory fit perspective of reward preferences in a health club setting. Journal of the Academy of Marketing Science, 38(5), 604-616.

Dweck, C. S., Chiu, C., \& Hong, Y. (1995). Implicit theories and their role in judgments and reactions: A word from two perspectives. Psychological Inquiry, 6(4), 267-285.

Evans-Lacko, S., Malcolm, E., West, K., Rose, D., London, J., Rüsch, N., Little, K., Henderson, C., \& Thornicroft, G. (2013). Influence of time to Change's social marketing interventions on stigma in England 2009-2011. British Journal of Psychiatry, 202, s77-s88.
Freimuth, V. S., Hammond, S. L., Edgar, T., \& Monahan, J. L. (1990). Reaching those at risk: A content-analytic study of AIDS PSAs. Communication Research, 17(6), 775-791.

Friedman, R. R., \& Puhl, R. M. (2012). Weight bias; a social justice issue: A policy brief. New Haven, CT: Rudd Center for Food Policy and Obesity, Yale University.

Frosch, D. L., Kimmel, S., \& Volpp, K. (2008). What role do lay beliefs about hypertension etiology play in perceptions of medication effectiveness? Health Psychology, 27(3), 320-326.

Gaebel, W, Zäske, H., \& Baumann, A.E. (2006). The relationship between mental illness severity and stigma. Acta Psychiatrica Scandinavica, 113(s429), 41-45.

Ghaemi, S. N. (2009). The rise and fall of the biopsychosocial model. British Journal of Psychiatry, 195(1), 3-4.

Gold, L. H. (2014). DSM-5 and the assessment of functioning: The World Health Organization disability assessment schedule 2.0 (WHODAS 2.0). Journal of the American Academy of Psychiatry and the Law Online, 42(2), 173-181.

Guze, S. B. (1992). Why psychiatry is a branch of medicine. New York: Oxford University Press.

Hanisch, S. E., Twomey, C. D., Szeto, A., Birner, U. W., Nowak, D., \& Sabariego, C. (2016). The effectiveness of interventions targeting the stigma of mental illness at the workplace: A systematic review. BMC Psychiatry, 16(1), 1-11.

Haslam, N., Rothschild, L., \& Ernst, D. (2002). Are essentialist beliefs associated with prejudice? British Journal of Social Psychology, 41(1), 87-100.

Higgins, E. T. (2005). Value from regulatory fit. Current Directions in Psychological Science, 14(4), 209-213.

Hong, Y., Chiu, C., \& Dweck, C. S. (1995). Implicit theories of intelligence. In Efficacy, agency, and self-esteem (pp. 197-216). New York: Springer.

Jain, S. P., Mathur, P., \& Maheswaran, D. (2009). The influence of consumers' lay theories on approach/avoidance motivation. Journal of Marketing Research, 46(1), 56-65.

Jaini, P. A., \& Lee, J. S. H. (2015). A review of 21 st century utility of a biopsychosocial model in United States medical school education. Journal of Lifestyle Medicine, 5(2), 49-59.

Kahneman, D. (2011). Thinking, fast and slow. New York: Macmillan.

Keller, P. A., \& Lehmann, D. A. (2008). Designing effective health communications: A meta-analysis. Journal of Public Policy \& Marketing, 27(2), 117-130.

Kiesler, D. J. (1999). Beyond the disease model of mental disorders. Westport, CT: Greenwood Publishing Group.

Kotler, P. (2011). Reinventing marketing to manage the environmental imperative. Journal of Marketing, 75(4), 132-135.

Kvaale, E. P., Gottdiener, W. H., \& Haslam, N. (2013). Biogenetic explanations and stigma: A meta-analytic review of associations among laypeople. Social Science \& Medicine, 96, 95-103.

Labroo, A. A., \& Mukhopadhyay, A. (2009). Lay theories of emotion transience and the search for happiness: A fresh perspective on affect regulation. Journal of Consumer Research, 36(2), 242-254.

Lee, N. R., \& Kotler, P. (2011). Social marketing: Influencing behaviors for good. Thousand Oaks, CA: Sage Publications Inc..

Levy, S. R., Stroessner, S. J., \& Dweck, C. S. (1998). Stereotype formation and endorsement: The role of implicit theories. Journal of Personality and Social Psychology, 74, 1421-1436.

Lin, L., \& McFerran, B. (2016). The (ironic) dove effect: Use of acceptance cues for larger body types increases unhealthy behaviors. Journal of Public Policy \& Marketing, 35(1), 76-90.

Lincoln, T. M., Arens, E., Berger, C., \& Rief, W. (2008). Can antistigma campaigns be improved? A test of the impact of biogenetic vs. psychosocial causal explanations on implicit and explicit attitudes to schizophrenia. Schizophrenia Bulletin, 34(5), 984-994.

Link, B. G., Phelan, J. C., Bresnahan, M., Stueve, A., \& Pescosolido, B. A. (1999). Public conceptions of mental illness: Labels, causes, 
dangerousness, and social distance. American Journal of Public Health, 89(9), 1328-1333.

Lyndon, A. E., Crowe, A., Wuensch, K. L., McCammon, S. L., \& Davis, K. P. (2016). College students' stigmatization of people with mental illness: Familiarity, implicit person theory, and attribution. Journal of Mental Health, 1(5).

Moorman, C., \& Matulich, E. (1993). A model of consumers' preventive health behaviors: The role of health motivation and health ability. Journal of Consumer Research, 20(2), 208-228.

Moses, T. (2010). Being treated differently: Stigma experiences with family, peers, and school staff among adolescents with mental health disorders. Social Science \& Medicine, 70(7), 985-993.

Motyka, S., Grewal, D., Puccinelli, N. M., Roggeveen, A. L., Avnet, T., Daryanto, A., de Ruyter, K., \& Wetzels, M. (2014). Regulatory fit: A meta-analytic synthesis. Journal of Consumer Psychology, 24(3), 394-410.

Plaks, J. E., Grant, H., \& Dweck, C. S. (2005). Violations of implicit theories and the sense of prediction and control: Implications for motivated person perception. Journal of Personality and Social Psychology, 88(2), 245-262.

Plaks, J. E., Stroessner, S. J., Dweck, C. S., \& Sherman, J. W. (2001). Person theories and attention allocation: Preferences for stereotypic versus counterstereotypic information. Journal of Personality and Social Psychology, 80(6), 876-893.

Puhl, R. M., \& Heuer, C. A. (2010). Obesity stigma: Important considerations for public health. American Journal of Public Health, 100(6), 1019-1028.

Rattan, A., \& Georgeac, O. A. (2017). Understanding intergroup relations through the lens of implicit theories (mindsets) of malleability. Social and Personality Psychology Compass, 11(4), 1-17.

Read, J., Haslam, N., Sayce, L., \& Davies, E. (2006). Prejudice and schizophrenia: A review of the 'mental illness is an illness like any other' approach. Acta Psychiatrica Scandinavica, 114(5), 303-318.

Rochlen, A.B., Whilde, M.R., \& Hoyer, W.D. (2005). The real men. Real depression campaign: Overview, theoretical implications, and research considerations. Psychology of Men \& Masculinity, 6(3), 186.

Rüsch, N., Todd, A. R., Bodenhausen, G. W., \& Corrigan, P. W. (2010). Do people with mental illness deserve what they get? Links between meritocratic worldviews and implicit versus explicit stigma. European Archives of Psychiatry and Clinical Neuroscience, $260(8), 617-625$.

Rüsch, N., \& Xu, Z. (2017). Strategies to reduce mental illness stigma. In The stigma of mental illness-end of the story? (pp. 451-467). New York: Springer International Publishing.

Sampogna, G., Bakolis, I., Evans-Lacko, S., Robinson, E., Thornicroft, G., \& Henderson, C. (2017). The impact of social marketing campaigns on reducing mental health stigma: Results from the 2009-2014 time to change programme. European Psychiatry, 40, 116-122.

Schoenbachler, D. D., Ridnour, R. E., \& Humes, K. (1996). Sensation seeking and the effectiveness of physical and social threat drug prevention PSA messages. Journal of Nonprofit \& Public Sector Marketing, 4(1-2), 51-73.
Schomerus, G., Matschinger, H., \& Angermeyer, M. C. (2007). Familiarity with mental illness and approval of structural discrimination against psychiatric patients in Germany. Journal of Nervous and Mental Disease, 195(1), 89-92.

Socall, D. W., \& Holtgraves, T. (1992). Attitudes toward the mentally ill. Sociological Quarterly, 33(3), 435-445.

Szeto, A. C., \& Dobson, K. S. (2010). Reducing the stigma of mental disorders at work: A review of current workplace anti-stigma intervention programs. Applied and Preventive Psychology, 14(1), 4156.

Teachman, B. A., Wilson, J. G., \& Komarovskaya, I. (2006). Implicit and explicit stigma of mental illness in diagnosed and healthy samples. Journal of Social and Clinical Psychology, 25(1), 75-95.

Tranulis, C., Goff, D., Henderson, D. C., \& Freudenreich, O. (2014). Becoming adherent to antipsychotics: A qualitative study of treatment-experienced schizophrenia patients. Psychiatric Services, 62(8), 888-892.

United Nations. (2018). The sustainable development goals report 2018. New York: United Nations.

Wang, W., Keh, H. T., \& Bolton, L. E. (2009). Lay theories of medicine and a healthy lifestyle. Journal of Consumer Research, 37(1), 80 97.

WHO. (2010). Mhgap intervention guide for mental, neurological and substance use disorders in non-specialized health settings: Mental health gap action programme (Mhgap). Geneva: World Health Organization.

WHO. (2013). Mental health action plan 2013-2020. Geneva: World Health Organization.

WHO. (2017a). Improving access to and appropriate use of medicines for mental disorders. Geneva: World Health Organization.

WHO (2017b), Weight bias and obesity stigma: considerations for the WHO European Region Geneva: World Health Organization.

Witte, K. (1996). Predicting risk behaviors: Development and validation of a diagnostic scale. Journal of Health Communication, 1(4), 317 342.

Yanos, P. T., Roe, D., \& Lysaker, P. H. (2010). The impact of illness identity on recovery from severe mental illness. American Journal of Psychiatric Rehabilitation, 13(2), 73-93.

Yorkston, E. A., Nunes, J. C., \& Matta, S. (2010). The malleable brand: The role of implicit theories in evaluating brand extensions. Journal of Marketing, 74(1), 80-93.

Zhao, G., \& Pechmann, C. (2007). The impact of regulatory focus on adolescents' response to antismoking advertising campaigns. Journal of Marketing Research, 44(4), 671-687.

Publisher's note Springer Nature remains neutral with regard to jurisdictional claims in published maps and institutional affiliations. 